\title{
Air Gun Test Evaluation
}

James J. Carleton II, Larry Fox, Clifford R. Rudy

January 15, 1992

\section{MOUND}

operated by

I. EERE MOUND APPLIED TECHNOLOGIES

for the

U. S. DEPARTMENT OF ENERGY

Contract No. DE-AC04-88DP43495 


\section{DISCLAMER}

This report was prepared as an account of work sponsored by an agency of the United States Government. Nelther the United States Governmeni nor any agency thereof. nor any of thelr employees. makes any warranty, express or implled. or assumes any legal llabllity or responsiblity for the accuracy. completeness. or usefulness of any information, apparatus, product. or process disclosed. or represents that its use would not iniringe prlvately owned rights. Reference herein to any spedfic commerclal produot. process. or service by trade name. trademark. manufacturer. or otherwise. does not necessarily constltute or imply its endorsement. recommendation. or favoring by the United States Government or any agency thereof. The vlews and oplnions of authors expressed herein do not necessarlly state or reflect those of the United States Government or any agency thereof.

This report has been reproduced directly from the best avallable copy.

Avallable to DOE and DOE contractors from:

Office of Sclentiflc and Technlcal Information

P.O. Box 62

Oak Pidge. TN 37831

Prlces avallable from $(615) 576-8401$. FTS 626-8401

Avallable to the publle from:

National Tochnical information Service

U.S. Department of Commerce

5285 Port Royal Rd.

Springfield. VA 22161 


\section{DISCLAIMER}

This report was prepared as an account of work sponsored by an agency of the United States Government. Neither the United States Government nor any agency Thereof, nor any of their employees, makes any warranty, express or implied, or assumes any legal liability or responsibility for the accuracy, completeness, or usefulness of any information, apparatus, product, or process disclosed, or represents that its use would not infringe privately owned rights. Reference herein to any specific commercial product, process, or service by trade name, trademark, manufacturer, or otherwise does not necessarily constitute or imply its endorsement, recommendation, or favoring by the United States Government or any agency thereof. The views and opinions of authors expressed herein do not necessarily state or reflect those of the United States Government or any agency thereof. 


\section{DISCLAIMER}

Portions of this document may be illegible in electronic image products. Images are produced from the best available original document. 
MLM-3730

UC-706

\section{Air Gun Test Evaluation}

James J. Carleton II, Larry Fox, Clifford R. Rudy

Issued: January 15,1992

\section{MOUND}

operated by EEE MOUND APPLIED TECHNOLOGIES

P.O. Box 3000. Miamisburg, Ohio 45343-3000

for the

U. S. DEPARTMENT OF ENERGY

Contract No. DE-AC04-88DP43495

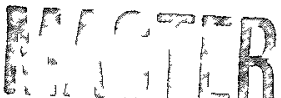




\section{Contents}

Page

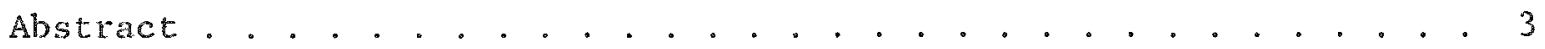

Apparatus Description. . . . . . . . . . . . . . . . . . . . 3

Experimental plan. . . . . . . . . . . . . . . . 6

Evaluation of Ranted Results . . . . . . . . . . . . . . . . 12

HF Series. . . . . . . . . . . . . . . . . . . . . 12

LF Series. . . . . . . . . . . . . . . . . . . 18

Rating Analysis Results. . . . . . . . . . . . . . . . . 20

Analysis of Accelaration ves. Frequency Data. . . . . . . . . . 22

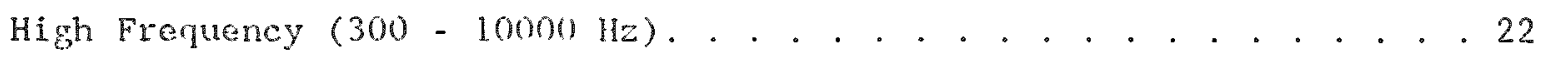

Low Frequency $(300-2000 \mathrm{~Hz})$. . . . . . . . . . . . . . . 30

Selection of Standard Operating Condition. . . . . . . . . . . . 38

Experimental Observations. . . . . . . . . . . . . . . . . . . . . 38

Acknowledgments. . . . . . . . . . . . . . . . . . . . . 39

References. . . . . . . . . . . . . . . . . . . . 40

Distribution . . . . . . . . . . . . . . . . . . . . . . 41 


\section{Abstract}

A mechanical shock testing apparatus is used for testing the response of components subject to large accelerations in hostile environments. The test acceleration is provided by the impact of a bullet against a plate on which the component to be tested is mounted. This report describes a series of experiments that were performed to determine the dependence of the air gun test apparatus performance on incremental changes in the hardware configurations, changes in the pressure used to drive the bullet, and different accelerometers. The effect of variation of these expeximental factors on the measured acceleration was detemined using a Taguchi screening experimental design. Experimental settings were determined that can be used to operate the tester with a measured output within acceleration specifications.

\section{Apparatus Description}

The major components of the air gun shock tester consist of a hanging plate suspended in front of 3 -in. diameter, 5-ft long gun barrel. The impulse is provided by a bullet propelled by a sudden release of gas pressure. The struck plate resonates providing the necessary acceleration. A large plate provides the desired acceleration spectrun at lower frequencies, and an alternate small plate at higher frequencies. The component to be tested is mounted in a fixture and the fixture is then attached to the appropriate plate in one of three perpendicular orientations $(X, Y, Z)$. An accelerometer is attached to the mounted fixture and another to the resonant plate. The accelerometer-fixture centerline is approximately the same as the gun barrel centerline. The accelerometer that is fastened directly to the plate provides a signal that triggers a Nicolet storage oscilloscope which records the conditioned signal from the other accelerometer. The speed of the bullet in the gun barrel is calculated from the transit time between two photocells. A schematic of the air gun setup is shown in Figure 1, and a photograph of the tester is shown in Figure 2. Testing can be performed at different enviromental temperatures. 


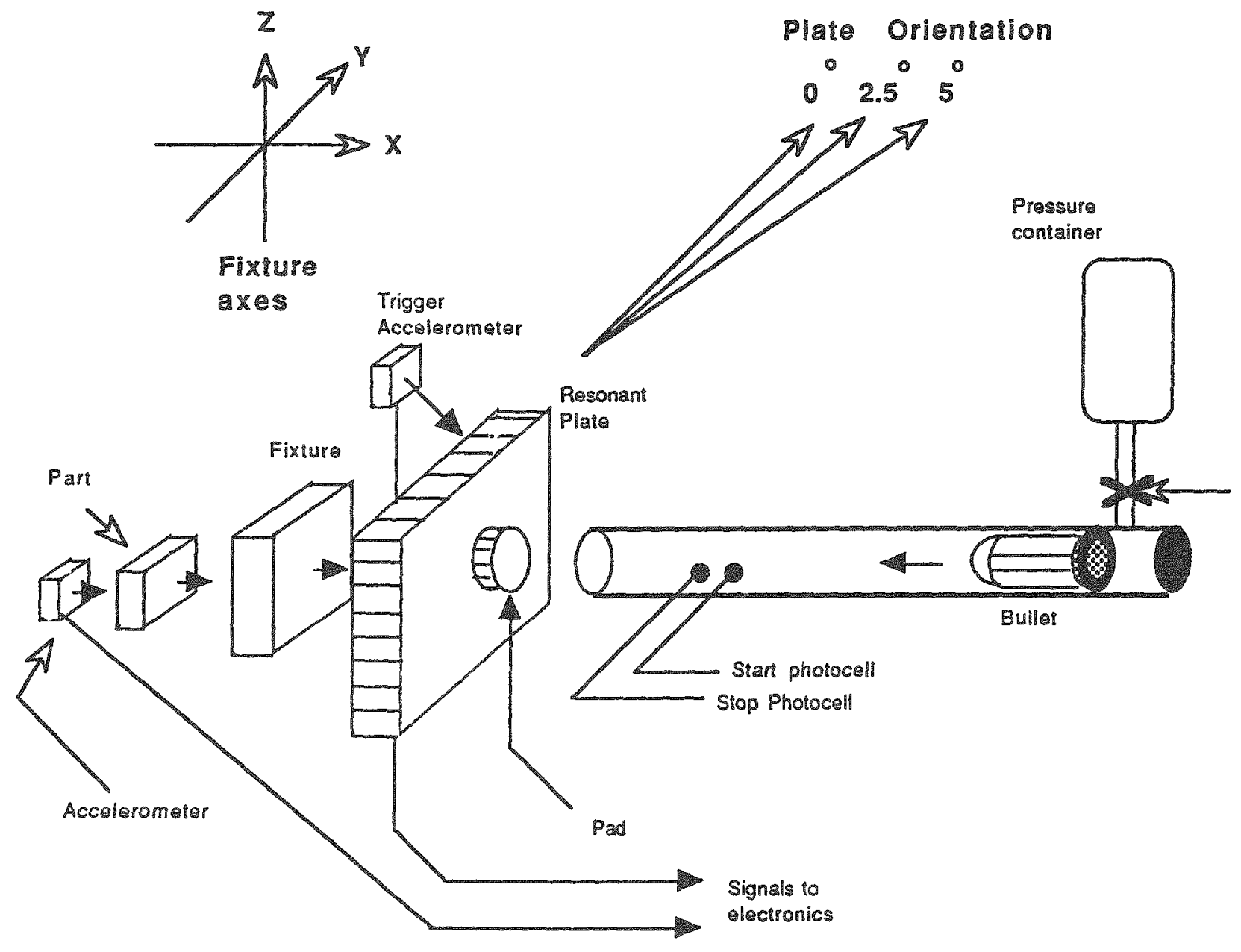

Figure 1 - Schematic of air gun tester. 


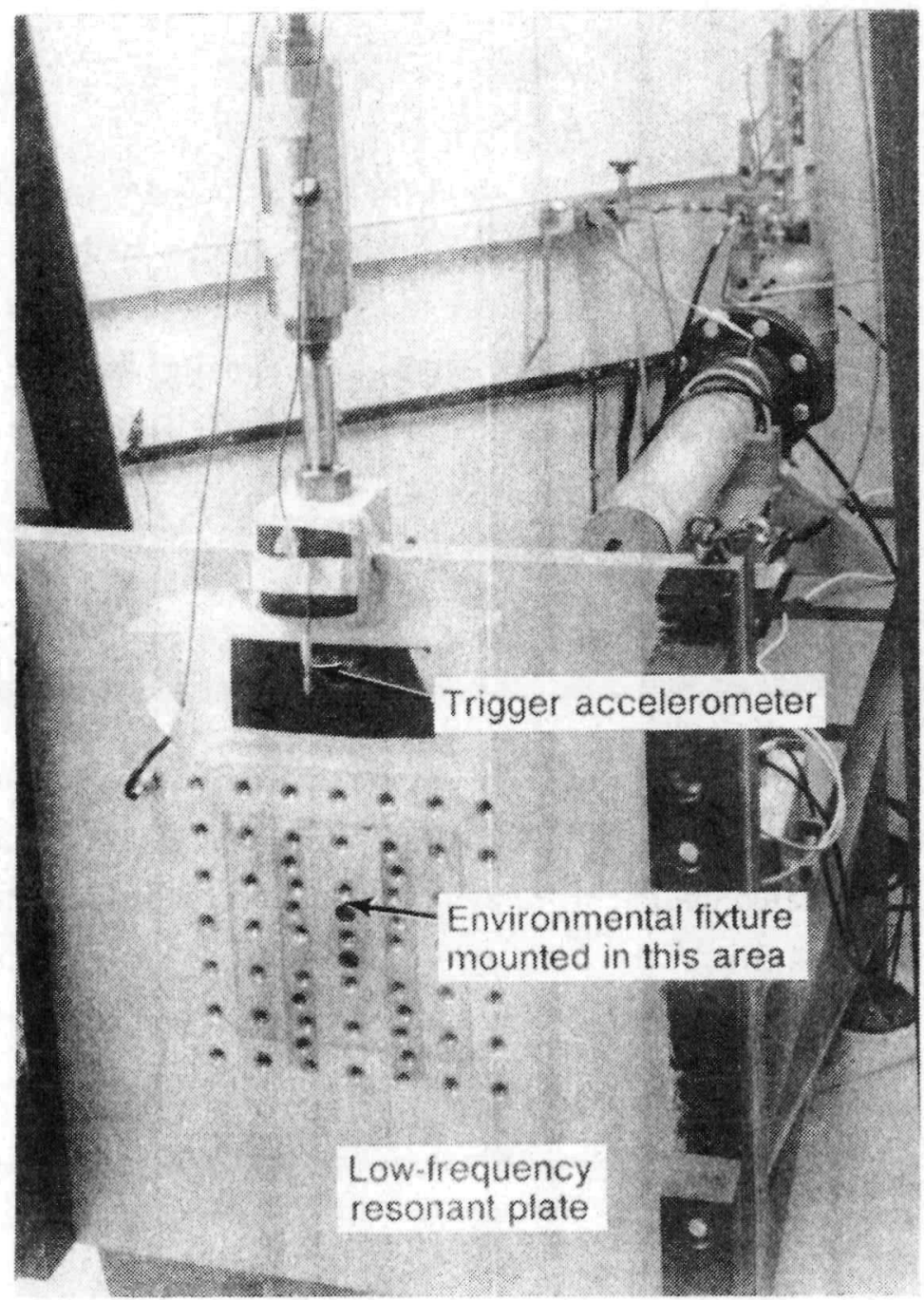

Figure 2 - Photograph of air gun tester. 
The primary data collected consists of the acceleration as a function of time. A typical impulse spectrum with the high-frequency and low-frequency plates are shown in Figures 3 and 4 . This signal is digitized and a fast fourier transform, applied to the data from a computer program, transforms it into an acceleration vs. frequency plot such as the ones shown in Figure 4 for both high-and low-frequency plates. The procedural sequence for shock testing is shown in Figure 5 .

\section{Experimental Plan}

The test apparatus must be capable of delivering accelerations within specification limits, and initial testing of components had yielded results that were outside those limits. In order to determine the cause of this problem, an experimental plan using a Taguchi screening experimental design was chosen. Screening designs such as this can be used to examine the effect of changes in multiple experimental factors with relatively few experiments.

From a detailed review of the procedure and apparatus, the factors that were determined to be the most important along with their identifiers or levels are listed in Table 1 . The bullet weight (G) factors listed in this table were eliminated from further consideration after additional study. High-Erequency (HF) testing normally employs the light bullet, whereas low-frequency (LF) testing uses the heavy bullet. It was found that by increasing the pressure the light bullet could be used to excite the first bending mode of the low-frequency plate. Elimination of the heavy bullet as a factor simplifies the test procedure for routine measurements.

Satisfactory results were obtained with an aluminum pad for the HF tests and the felt pad for the LF tests.

Three of the five factors listed in Table 1 were not factors that could be optimized, that is, one cannot choose the best of the three listed because 

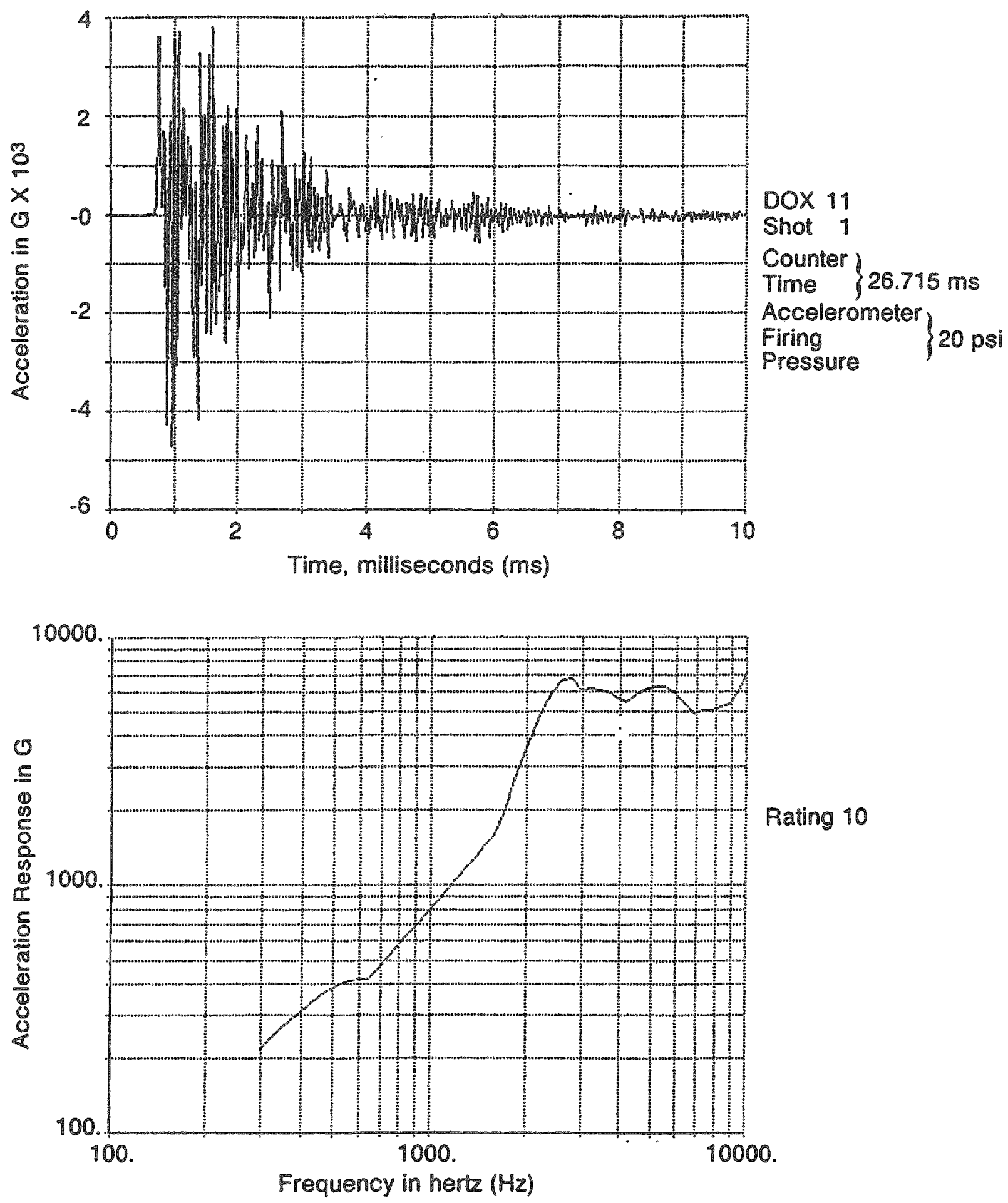

Figure 3 - Shock impulse in time and frequency domain for testing with high-frequency plate. 

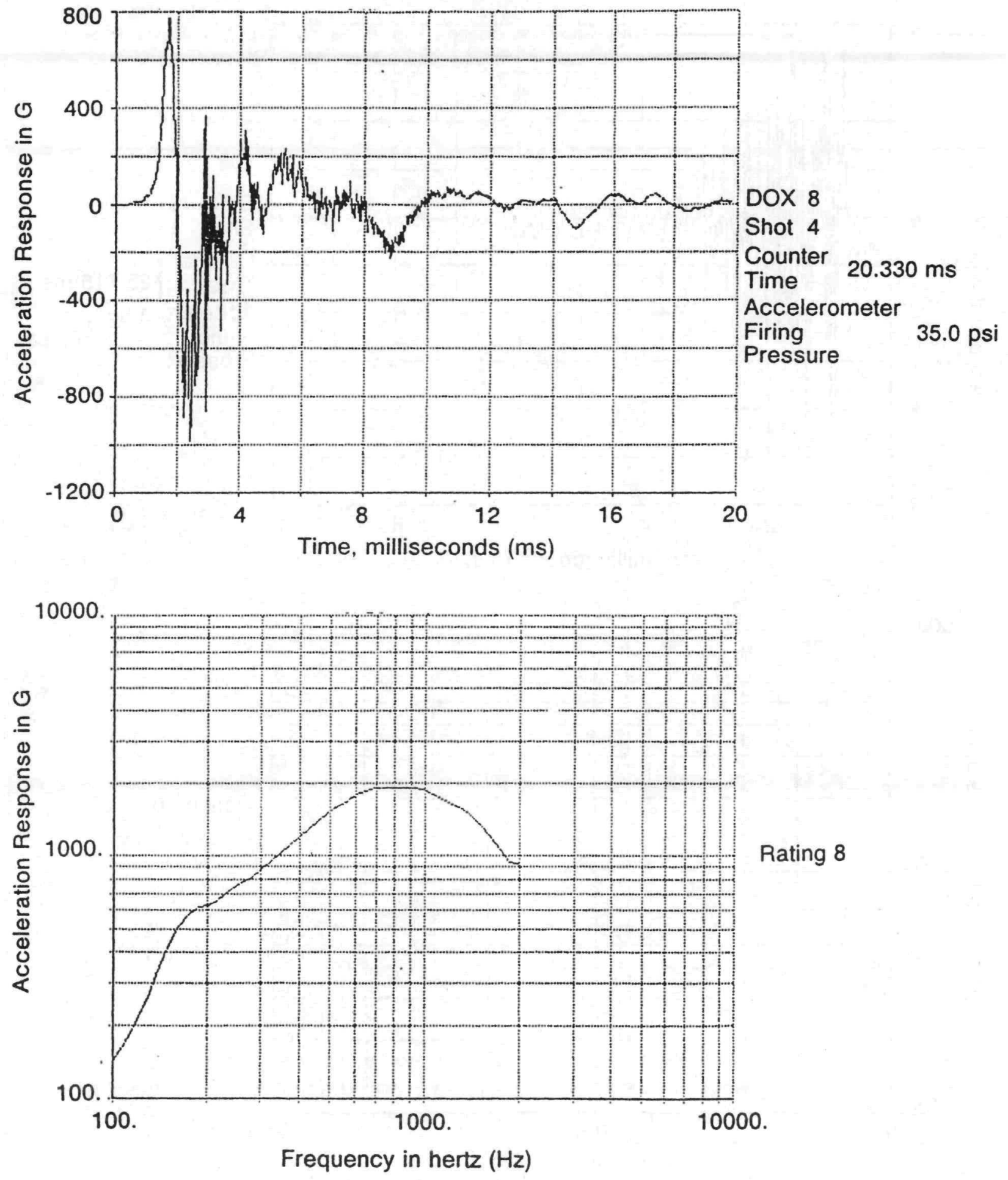

Figure 4 - Shock impulse in time and frequency domain for testing with low-frequency plate. 


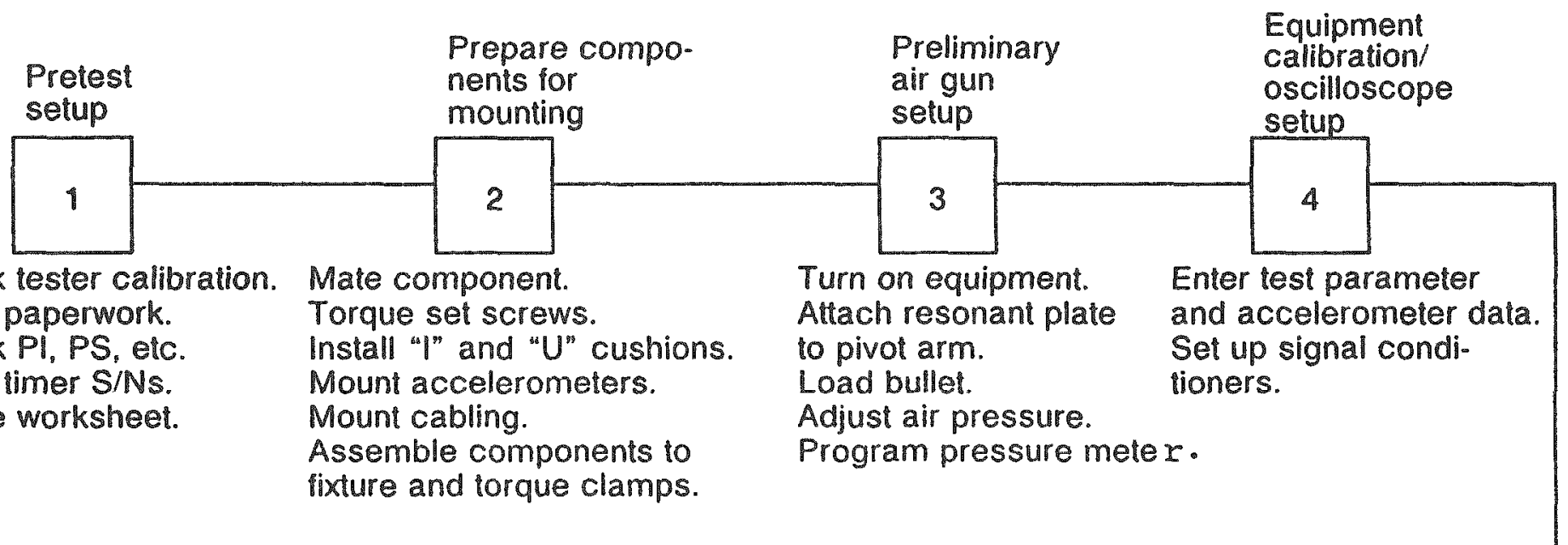

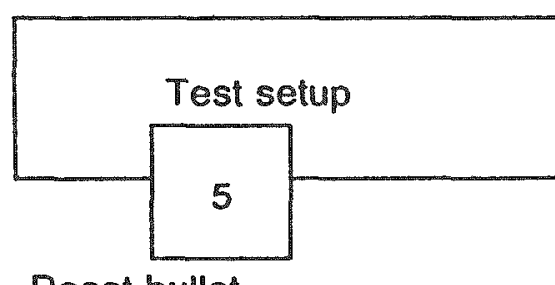

Reset bullet.

Mount loaded fixture to

plate.

Connect accelerometer

cables to fixture.

Resel pivot arm

Ensure resonant plate is

perpendicular to barrel.

Close room door and lock.

Initiate test at control panel.

Ready for test.

Post test

procedures

\begin{tabular}{|c|l|}
\hline 6 & 7 \\
\hline
\end{tabular}

Ensure scope settings

are correct.

Arm tester.

Allow pressure to bleed

off in firing tank reservoir.

Actuate dump valve to

fire bullet.
Compile data.

Analyze results.

Special Exception

Report needed? 


\begin{tabular}{|c|c|c|c|}
\hline \multirow[t]{2}{*}{ Facror } & \multicolumn{3}{|c|}{ Levels } \\
\hline & 1 & 2 & 3 \\
\hline (A) Fixture $S / N^{*}$ & 33 & 39 & 45 \\
\hline (B) Fixture Axis ${ }^{*}$ & $\bar{x}$ & $\bar{Y}$ & $z$ \\
\hline (C) Resonant Plate Angle & $0^{\circ}$ & 50 & $2.5^{\circ}$ \\
\hline (D) Charge/Firing Pressure & $17 \mathrm{psi}$ & $20 \mathrm{psi}$ & 23 psi \\
\hline LF & $30 \mathrm{psi}$ & $35 \mathrm{psi}$ & $40 \mathrm{psi}$ \\
\hline $\begin{array}{l}\text { (E) Accelerometer S/N * } \\
\text { (cal factors) }\end{array}$ & $\begin{array}{l}\text { BT75 } \\
(0.1651)\end{array}$ & $\begin{array}{l}\text { BN92 } \\
(0.1524)\end{array}$ & $\begin{array}{l}\text { BW49 } \\
(0.1749)\end{array}$ \\
\hline (F) Impact Pad & Aluminum & $\ldots$ & $\ldots$ \\
\hline$L F^{* * \hbar}$ & Felt & (Delron) & --- \\
\hline (G) Bullet Weight(LF only) & Light & (Heavy) & $-\cdots$ \\
\hline
\end{tabular}

* not a factor that can be optimized. All three axis orientations, fixtures, or accelerometers are used.

* Only the felt pad was used during Taguchi LF runs; the accelerations obtained with a Delron pad were unacceptable

*** Only the light bullet was used, with acceptable results being obtained for both HF and LF tests.

TABLE 1 - AIR GUN EXPERIMENTAL FACTORS 
the production testing involves evaluation at all conditions. These factors are axis configurations, fixtures, and accelerometers. All three axis configurations of a component must be tested, and it is not feasible to use only one accelerometer or fixture during testing of multiple units.

Two sets of experiments were performed: One set with the HF plate and the other with the LF plate. A different set of pressures was used with the two different plates as indicated in Table 1. A felt pad was used with all LF tests and an aluminum block used as the pad for the HF tests. The same leve1s for all other factors were used for both tests.

An efficient procedure for simultaneously studying the effect of the factors uses experimental design techniques. There are $3^{5}(=243)$ possible combinations of the five factors ( $A-E$ ) that can be used for each test. Experimental design allows the significance of each factor to be determined with 27 combinations, $1 / 9$ th of the total number of possibilities. In all, 54 combinations were thus investigated, 27 for HF and 27 for LF. The design selected was a Taguchi L-27 matrix which allows up to 13 different factors to be investigated simultaneously [1,2]. The matrices followed for the HF and LF series are shown in Tables 2 and 3 . Two approaches were used to analyze the data. In one approach, the data were ranked on a scale ranging from the excellent (10) to unsatisfactory (2), according to how well the measured accelerations were within specification limits. In the other approach, the digital data at selected frequencies, spanning the range studied, were analyzed so that the effect of each factor could be evaluated at a number of specific frequencies. A description of the results of each approach are given below.

Multiple runs or "shots" were performed for one set of conditions. For example, the first run listed in Table 2 was performed with Fixture 33 oriented along the $\mathrm{X}$ axis, with accelerometer $\mathrm{BT} 75$, resonant plate at $0^{\circ}$ angle and a firing pressure of $17 \mathrm{psi}$. The table indicates that four replicate runs were performed on 4-5-90 and four on 5-14-90. In a11, 109 
shots were performed with calibrated accelerometers for the HF runs and 108 for the LF runs. The actual. run order for the series of 27 runs was random rather than the order given in Tables 2 and 3.

\section{Evaluation of Ranked Results}

The following evaluation system was used to rate how the shock spectra met the product specification.

- Meets specification with no fluctuations in spectra: 10

- Meets specification with fluctuations/flaws in spectra: 8

- Over test limit at upper end of test specification: 6

- Over test limit at lower end of specification: 6

- Over test limit at both ends of specification: 4

- Under test limit at any point: 2

The results of the HF and LF tests are shown in the 1ast columns of Tables 2 and 3. Averages of the replicate shots are used to evaluate the effect of each experimental factor. Scores versus factor levels are plotted on graphs and a visual evaluation is performed to see if significant differences can be observed. An evaluation of the five classes of factors for the HF series is shown in Figure 6. The indications for those five factors are discussed in the following section.

\section{HF Series}

Axis: The data show that the $\mathrm{X}$ axis configuration is definitely worse than the others. 


\begin{tabular}{|c|c|c|c|c|c|c|c|c|c|c|c|c|c|c|}
\hline $\begin{array}{l}\text { Mo. } \\
\text { Col. }\end{array}$ & (bxis) & $\begin{array}{c}\text { (E) } \\
\text { Accoll }\end{array}$ & 3 & 4 & (0) & 6 & 7 & $\begin{array}{l}\text { (A) } \\
\text { Fot }\end{array}$ & (C) & 10 & 11 & 12 & 13 & $\begin{array}{l}\text { Ranking } \\
\text { Reath }\end{array}$ \\
\hline 1 & $x$ & ET75 & 1 & 1 & 17 & 1 & 1 & 33 & 0 & 1 & 1 & 1 & 1 & $\begin{array}{l}4-5-90 / 5014-90 \\
2 ; 2 ; 2: 2 / 2 ; 2 ;\end{array}$ \\
\hline 2 & $x$ & 8775 & 1 & 1 & 20 & 2 & 2 & 38 & 5 & 2 & 2 & 2 & 2 & $\begin{array}{l}4-5-30 / /-80 \\
2 ; 2 ; 2 ; 2 / 2 ; 2 ; 2 ; 2 \\
\end{array}$ \\
\hline 3 & $x$ & B775 & 1 & 1 & 23 & 3 & 3 & 45 & 2.5 & 3 & 3 & 3 & 3 & 6; \\
\hline 4 & $x$ & But92 & 2 & 2 & 17 & 1 & 1 & 39 & 5 & 2 & 3 & 3 & 3 & $2: 2 ; 2 ; 2$ \\
\hline 5 & $x$ & an:2 & 2 & 2 & 20 & 2 & 2 & 45 & 25 & 3 & 1 & 1 & 1 & $4: 4_{i}^{0} 4$ \\
\hline 6 & $x$ & Be492 & 2 & 2 & 23 & 3 & 3 & 33 & 0 & 1 & 2 & 2 & 2 & $604 ; 4$ \\
\hline 7 & $x$ & En449 & 3 & 3 & 17 & 1 & 1 & 45 & 25 & 3 & 2 & 2 & 2 & $2 ; 2 ; 2 ; 2$ \\
\hline 8 & $x$ & BNont9 & 3 & 3 & 20 & 2 & 2 & 33 & 0 & 1 & 3 & 3 & 3 & $8 ; 8 ; 8 ; 8$ \\
\hline 9 & $x$ & Bพ14 49 & 3 & 3 & 23 & 3 & 3 & 39 & 5 & 2 & 1 & 1 & 1 & $2 ; 8 ; 2: 2$ \\
\hline 10 & $Y$ & 8775 & 2 & 3 & 17 & 2 & 3 & 33 & 5 & 3 & 1 & 2 & 3 & $8 ; 2 ; 8 ; 8$ \\
\hline 11 & $Y$ & BT75 & 2 & 3 & 20 & 3 & 1 & 39 & 25 & 1 & 2 & 3 & 1 & $10 ; 10 ; 10 ; 10$ \\
\hline 12 & $Y$ & 8775 & 2 & 3 & 23 & 1 & 2 & 45 & 0 & 2 & 3 & 1 & 2 & $6 ; 8 ; 8 ; 8$ \\
\hline 13 & $Y$ & BN92 & 3 & 1 & 17 & 2 & 3 & 39 & 2.5 & 1 & 3 & 1 & 2 & $10 ; 10 ; 10 ; 10$ \\
\hline 14 & $Y$ & BN92 & 3 & 1 & 20 & 3 & 1 & 45 & 0 & 2 & 1 & 2 & 3 & $10 ; 10 ; 8:$ \\
\hline 15 & $Y$ & BN92 & 3 & 1 & 23 & 1 & 2 & 33 & 5 & 3 & 2 & 3 & 1 & $6 ; 8 ; 10 ;$ \\
\hline 16 & $Y$ & BN49 & 1 & 2 & 17 & 2 & 3 & 45 & 0 & 2 & 2 & 3 & 1 & $10 ; 10 ; 10 ; 10$ \\
\hline 17 & $Y$ & Bu49 & 1 & 2 & 20 & 3 & 1 & 33 & 5 & 3 & 3 & 1 & 2 & $10 ; 10 ; 10 ; 10$ \\
\hline 18 & $Y$ & BN49 & 1 & 2 & 23 & 1 & 2 & 39 & 2.5 & 1 & 1 & 2 & 3 & $8 ; 8 ; 8 ; 8$ \\
\hline 19 & 2 & 8775 & 3 & 2 & 17 & 3 & 2 & 33 & 25 & 2 & 1 & 3 & 2 & $2 ; 10 ; 10 ; 10$ \\
\hline 20 & 2 & 8775 & 3 & 2 & 20 & 1 & 3 & 39 & 0 & 3 & 2 & 1 & 3 & $8: 8 ; 10$ \\
\hline 21 & 2 & 8775 & 3 & 2 & 23 & 2 & 1 & 45 & 5 & 1 & 3 & 2 & 1 & $8 ; 2 ; 2 ; 8$ \\
\hline 22 & $z$ & BN92 & 1 & 3 & 17 & 3 & 2 & 39 & 0 & 3 & 3 & 2 & 1 & $10: 10: 10: 10$ \\
\hline 23 & 2 & BN92 & 1 & 3 & 20 & 1 & 3 & 45 & 5 & 1 & 1 & 3 & 2 & $10 ; 8 ; 8 ;$ \\
\hline 24 & 2 & BN92 & 1 & 3 & 23 & 2 & 1 & 33 & 25 & 2 & 2 & 1 & 3 & $8 ; 4 ; 8$ \\
\hline 25 & 2 & BN49 & 2 & 1 & 17 & 3 & 2 & 45 & 5 & 1 & 2 & 1 & 3 & $2 ; 8 ; 2 ; 2$ \\
\hline 26 & 2 & EN48 & 2 & 1 & 20 & 1 & 3 & 33 & 25 & 2 & 3 & 2 & 1 & $10 ; 10: 10: 10$ \\
\hline 27 & $z$ & BWA 49 & 2 & 1 & 23 & 2 & 1 & 39 & 0 & 3 & 1 & 3 & 2 & $8: 9: 4: 4$ \\
\hline
\end{tabular}

TABLE 2 - TAGUCHI L27 MATRIX OF EXPERIMENTAL SETTINGS

FOR THE TESTS WITH THE HIGH-FREQUENCY PLATE. 


\begin{tabular}{|c|c|c|c|c|c|c|c|c|c|c|c|c|c|c|}
\hline $\begin{array}{l}\text { No. } \\
\text { Col. }\end{array}$ & $\begin{array}{l}(8) \\
\text { Axis }\end{array}$ & $\begin{array}{c}(\mathrm{E}) \\
\text { Acce! }\end{array}$ & 3 & 4 & $\begin{array}{c}\text { (D) } \\
\text { Pross }\end{array}$ & 6 & 7 & $\begin{array}{l}\text { (A) } \\
\text { Fixt }\end{array}$ & $\begin{array}{c}\text { (c) } \\
\text { Angie }\end{array}$ & 10 & 11 & 12 & 13 & $\begin{array}{l}\text { Ranking } \\
\text { Results }\end{array}$ \\
\hline 1 & $x$ & BT75 & 1 & 1 & 30 & 1 & 1 & 33 & 0 & 1 & 1 & 1 & 1 & $10 ; 10 ; 10 ; 10$ \\
\hline 2 & $x$ & 8775 & 1 & 1 & 35 & 2 & 2 & 39 & 5 & 2 & 2 & 2 & 2 & $10 ; 10 ; 10 ; 10$ \\
\hline 3 & $x$ & 8775 & 1 & 1 & 40 & 3 & 3 & 45 & 2.5 & 3 & 3 & 3 & 3 & $6 ; 6 ; 6 ; 6$ \\
\hline 4 & $x$ & BN92 & 2 & 2 & 30 & 1 & 1 & 39 & 5 & 2 & 3 & 3 & 3 & $8 ; 8 ; 8 ; 8$ \\
\hline 5 & $x$ & BN92 & 2 & 2 & 35 & 2 & 2 & 45 & 2.5 & 3 & 1 & 1 & 1 & $6 ; 6 ; 6 ; 6$ \\
\hline 6 & $x$ & BN92 & 2 & 2 & 40 & 3 & 3 & 33 & 0 & 1 & 2 & 2 & 2 & $4 ; 4 ; 4 ; 4$ \\
\hline 7 & $x$ & |8w49| & 3 & 3 & 30 & 1 & 1 & 45 & 2.5 & 3 & 2 & 2 & 2 & $10 ; 10 ; 10 ; 10$ \\
\hline 8 & $x$ & BW49 & 3 & 3 & 35 & 2 & 2 & 33 & 0 & 1 & 3 & 3 & 3 & $8 ; 8 ; 8 ; 8$ \\
\hline 9 & $x$ & 8149 & 3 & 3 & 40 & 3 & 3 & 39 & 5 & 2 & 1 & 1 & 1 & $8 ; 8 ; 8 ; 8$ \\
\hline 10 & $Y$ & 8775 & 2 & 3 & 30 & 2 & 3 & 33 & 5 & 3 & 1 & 2 & 3 & $2 ; 2 ; 2 ; 2$ \\
\hline 11 & $Y$ & 9775 & 2 & 3 & 35 & 3 & 1 & 39 & 2.5 & 1 & 2 & 3 & 1 & $10 ; 10 ; 10 ; 10$ \\
\hline 12 & $Y$ & $B T 75$ & 2 & 3 & 40 & 1 & 2 & 45 & 0 & 2 & 3 & 1 & 2 & $10 ; 10 ; 10 ; 10$ \\
\hline 13 & $Y$ & BN92 & 3 & 1 & 30 & 2 & 3 & 39 & 2.5 & 1 & 3 & 1 & 2 & $8 ; 8 ; 8 ; 8$ \\
\hline 14 & $Y$ & BN92 & 3 & 1 & 35 & 3 & 1 & 45 & 0 & 2 & 1 & 2 & 3 & $10 ; 10 ; 10 ; 10$ \\
\hline 15 & $Y$ & BN92 & 3 & 1 & 40 & 1 & 2 & 33 & 5 & 3 & 2 & 3 & 1 & $10 ; 10 ; 8 ; 8$ \\
\hline 16 & $Y$ & BW49 & 1 & 2 & 30 & 2 & 3 & 45 & 0 & 2 & 2 & 3 & 1 & $2 ; \quad 2 ; \quad 2 ; \quad 2$ \\
\hline 17 & $Y$ & BW49 & 1 & 2 & 35 & 3 & 1 & 33 & 5 & 3 & 3 & 1 & 2 & $10 ; 10 ; 10 ; 10$ \\
\hline 18 & $Y$ & BW49 & 1 & 2 & 40 & 1 & 2 & 39 & 2.5 & 1 & 1 & 2 & 3 & $8 ; 8 ; 8 ; 8$ \\
\hline 19 & 2 & 8775 & 3 & 2 & 30 & 3 & 2 & 33 & 2.5 & 2 & 1 & 3 & 2 & $2 ; 8 ; 2 ; 8$ \\
\hline 20 & $z$ & $B 775$ & 3 & 2 & 35 & 1 & 3 & 39 & 0 & 3 & 2 & 1 & 3 & $8 ; 8 ; 6 ; 6$ \\
\hline 21 & $z$ & $B 775$ & 3 & 2 & 40 & 2 & 1 & 45 & 5 & 1 & 3 & 2 & 1 & $8 ; 8 ; 10 ; 10$ \\
\hline 22 & 2 & BN92 & 1 & 3 & 30 & 3 & 2 & 39 & 0 & 3 & 3 & 2 & 1 & $8 ; 8 ; 8 ; 8$ \\
\hline 23 & $z$ & BN92 & 1 & 3 & 35 & 1 & 3 & 45 & 5 & 1 & 1 & 3 & 2 & $2 ; 8 ; \quad 8 ; 8$ \\
\hline 24 & 2 & BN92 & 1 & 3 & 40 & 2 & 1 & 33 & 2.5 & 2 & 2 & 1 & 3 & $6 ; 6 ; 6 ; 6$ \\
\hline 25 & 2 & BN49 & 2 & 1 & 30 & 3 & 2 & 45 & 5 & 1 & 2 & 1 & 3 & $8 ; 8 ; 8 ; 8$ \\
\hline 26 & 2 & BW49 & 2 & 1 & 35 & 1 & 3 & 33 & 2.5 & 2 & 3 & 2 & 1 & $10: 10 ; 10 ; 10$ \\
\hline 27 & Z & BW49 & 2 & 1 & 40 & 2 & 1 & 39 & 0 & 3 & 1 & 3 & 2 & $6 ; \quad 6 ; \quad 6 ; 6$ \\
\hline
\end{tabular}

TABLE 3 - TAGUCHI L27 MATRJX OF EXPERIMENTAL SETTINGS FOR THE TESTS WITH THE LOW-FREQUENCY PLATE. 


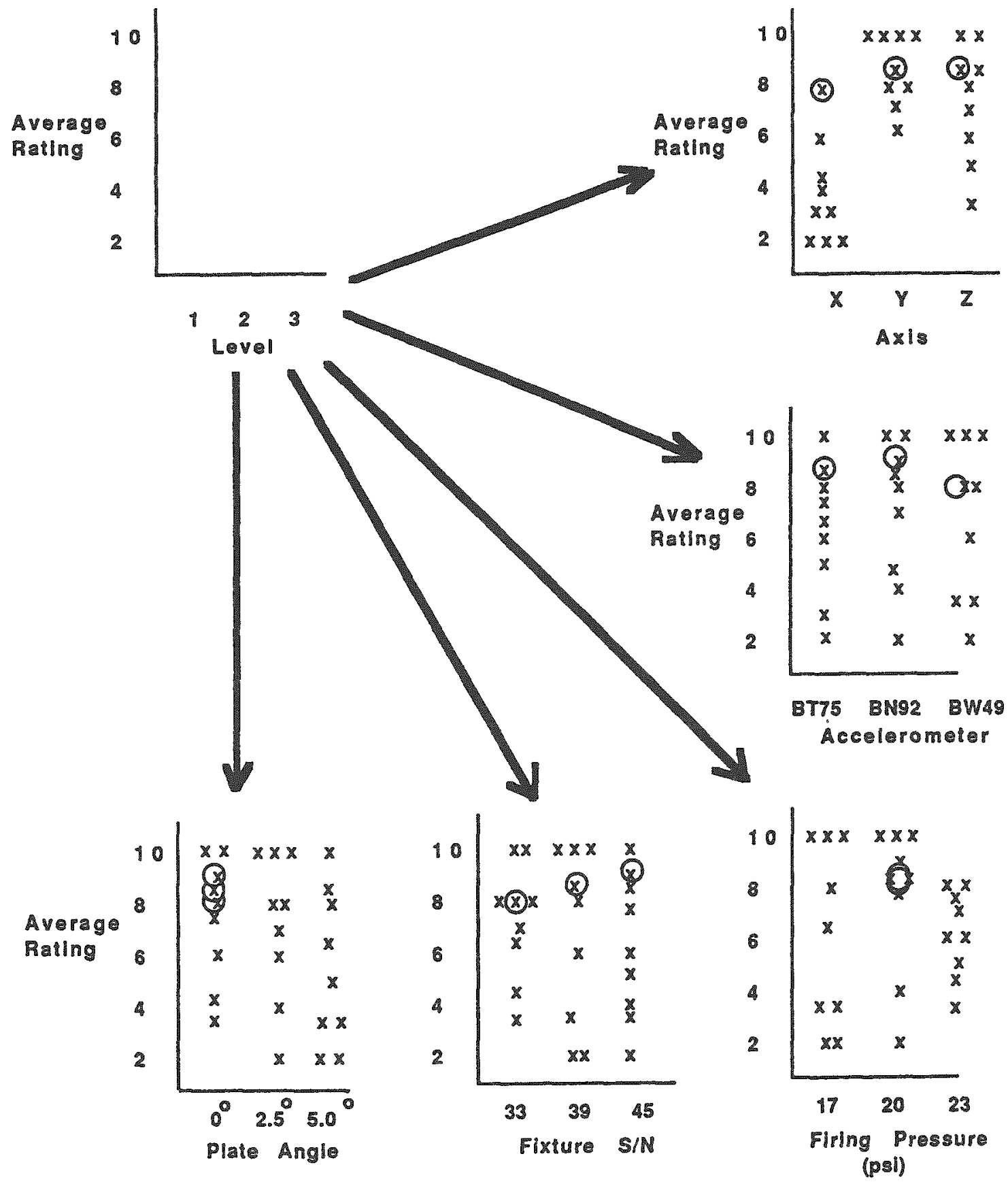

Figure 6 - Main effects for the five experimental factors, high-frequency plate runs. 
Accelwometer: This plot indicates that for different accelerometers (with the same manufacturer and model number), the test results are not significantly different. Large variability was observed for the results from all. three accelerometers.

Firing pressure: Larger variabilities obtained with firing pressures 17 and 20 psi. However, when the firing pressure was 23 psi, no optimum rating of 10 was observed. The $17 \mathrm{psi}$ results were overall the worst of the three indicating that this pressure should not be used.

Fixture: There is no difference between fixcures.

Plate Angle: The best results were obtained at the $0^{\circ}$ angle.

The circled data points shown on the graphs in Figure 6 correspond to a 20 psi firing pressure and $0^{\circ}$ relative plate angle which gave satisfactory results for all $\mathrm{HF}$ trials.

\section{Interactions}

Specific interactions between experimental factors can be examined. Several of the 10 possible interactions between the factors of this experinent are plotted in Figure 7. Most results of the 10 interactions were similar to the first two graphs plotted in the figure. In the first graph, which examines the axis-accelerometer interaction, all accelerometers act similarly for the $X, Y$, and $Z$ axes. A similar effect is seen for the axis-pressure interaction. For the third graph, fixture-angle, an apparent interaction is observed.

The $5^{\circ}$ data is low for surial number 39. The cause of this low data point, however, is the confounding of the data in this graph with the axis data. By exanination of the Taguchi matrix in Table 2, we see that the $\left(39,5^{\circ}\right)$ condition is synonymous with the $X$ axis and the other two points with the $Y$ 
Axis $x$ Accolerometer Interaction

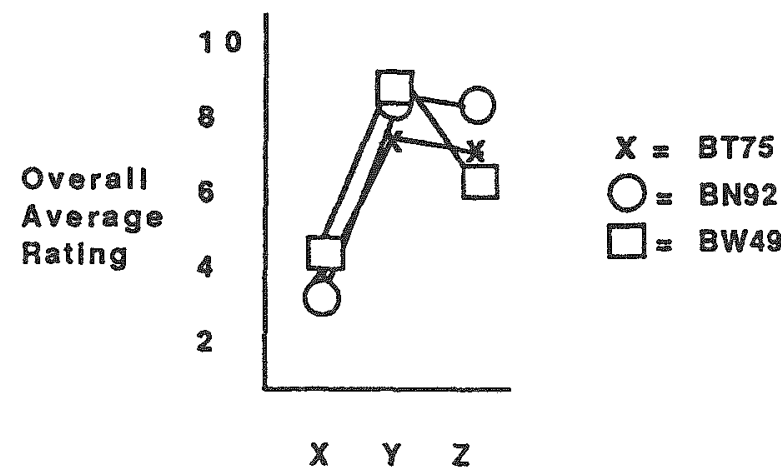

Axis $x$ Pressure Interaction

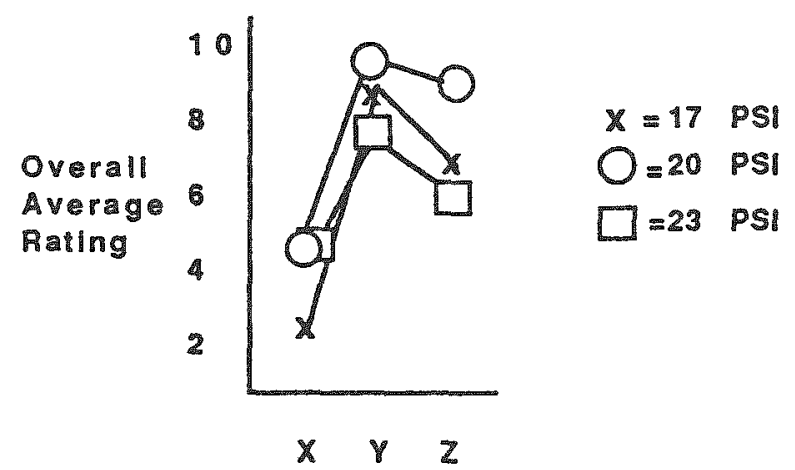

Fixture $x$ Angle Interaction

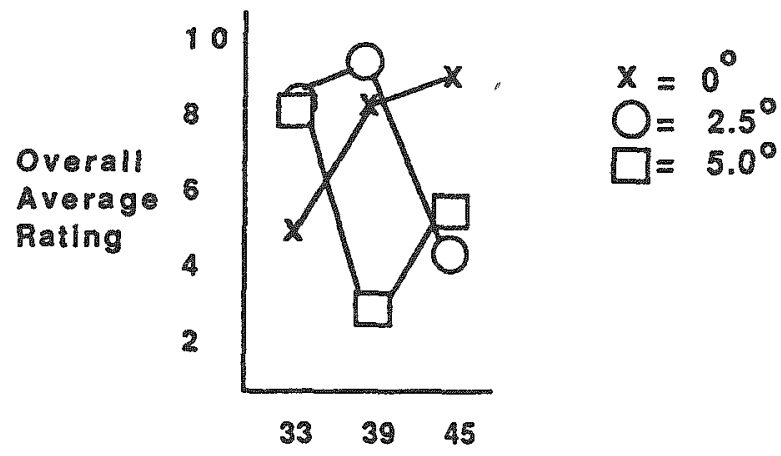

Serial Number
This graph shows the interaction between axis and accelerometar. The three accolerometers have simllar rasponses with different fixtur orientatlon, hence no Interaction is indicated.

No interaction.

Apparent interaction. The combination SN $=39$, angle $=5^{\circ}$ leads 10 a low result. The results on this plot, however, are contounded with axes, and the efrect of the $X$ axis, a definitely poor performing coniguration, is iso estimated with the $(39,5)$ dat point.

Figure 7 - Tests for interactions of experimental factors for high-frequency runs. 
and $z$ axes. Thus, the main axis effect is confounded with the interaction. The $X$ axis gave significantly worse results than the $Y$ and $Z$ axes as $c a n$ be seen from the graph in Figure 6 .

\section{LF Series}

Two runs of the 27 performed in the LF series were rated 2, unsatisfactory, because the accelerations dropped below the specification limit at $100 \mathrm{~Hz}$ by 5 to $10 \mathrm{~Hz}$. Of the remaining 25 runs, 23 were rated 6 or better. Better overal1 performance was obtained for the LF runs than for the HF ones. More alternative sets of operating conditions for the optimum operating conditions are possible. An evaluation of the five classes of factors is given in Figure 8. The high proportion of good scores for most of the runs indicates that there is less of an effect of varying experimental factors on the performance of the tester. The indications for those five factors are discussed below.

Axis: No conclusion was reached on which axes give the best result. The $Y$ axis results are the best and the worst.

Accelerometer: The accelerometers are equivalent.

Firing Pressure: A firing pressure of 35 psi gives the best results.

Fixture: No significant difference between fixture is seen.

Plate Angle: There is no significant difference. The $5^{\circ}$ plate angle gives the best results with 7 of 9 ratings greater than or equal to 8 . A possible explanation for this good performance of the $5^{\circ}$ angle, compared to the HF result, is that for the LF tests, the bullet impacts a felt pad mounted to the resonant plate, and this angle is not as critical as in HF testing where an aluminum block is used as the impact point. Therefore, the LF test 


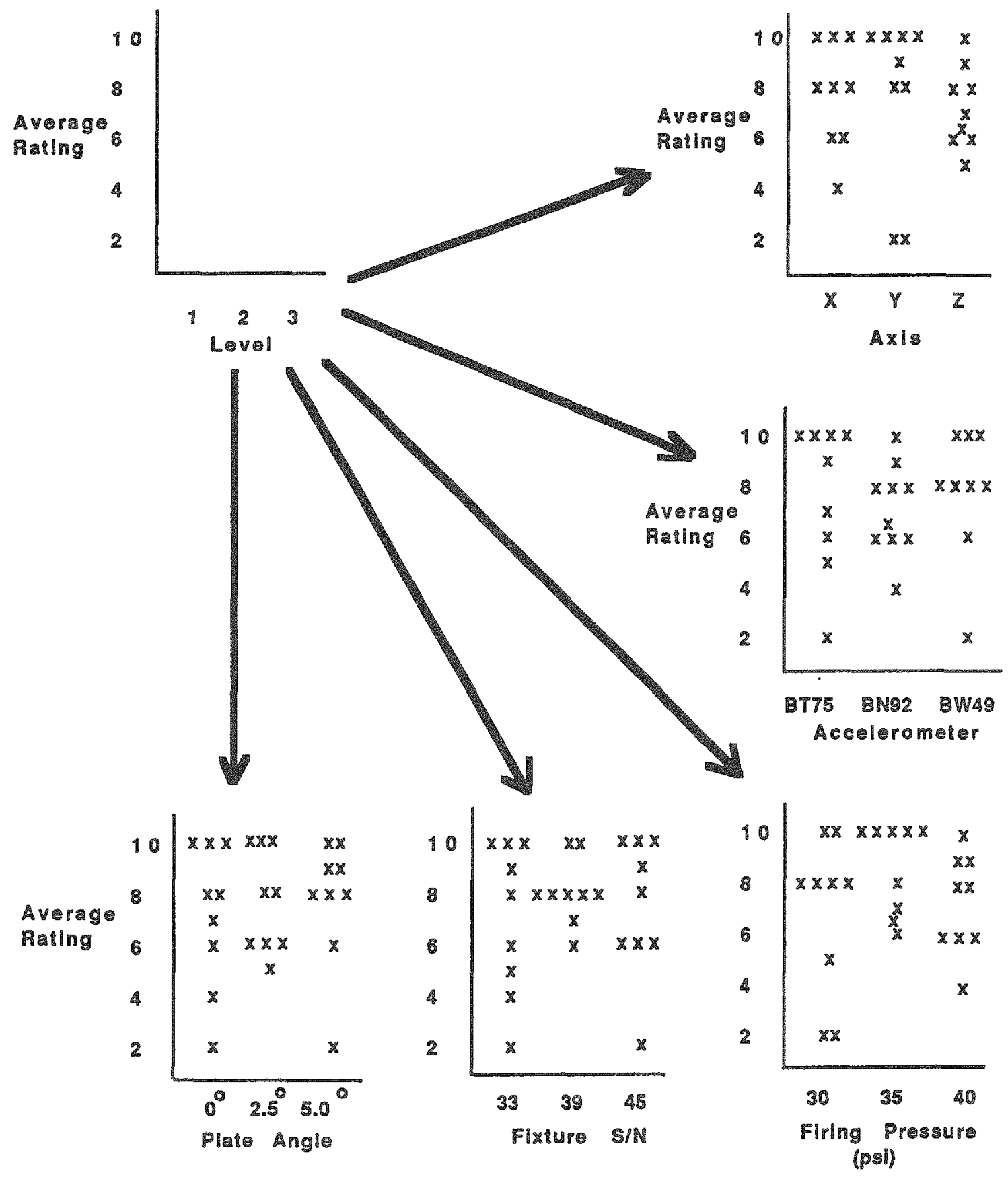

Figure 8 - Main effects for the five experimental factors, low-frequency plate runs. 
results are less sensitive to impact on the plate from the "corner" of the bullet nose.

Interactions

Some of the interactions between experimental factors are examined in the plots in Figure 9. Only one of the 10 possible two-factor interactions tested indicated an apparent interaction which is shown in the Figure. There is a good possibility that the two bad runs at 30 psi will happen to fall into one of the three possibilities for the other factors and give rise to an apparent interaction for one of them by chance. Thus, the interaction shown in this plot may be spurious. Other plots in figure 9 are typical of the "no interaction" plots that were observed.

\section{Rating Analysis Results}

High Frequency: The 20 psi firing pressure and $0^{\circ}$ plate angle experimental setup conditions gave consistently good results and thus should be considered as standard operating conditions for the high-frequency series of a component test with the air gun tester.

Low Frequency: The sensitivity to pressure and plate angle is much less for LF than that observed for the HF testing. Successful results were achieved for all three angles and pressures studied. When evaluating which conditions should become standard, other factors such as minimization of setup time become more important. Thus, it was decided to use 35 psi firing pressure and $0^{\circ}$ plate angle as the standard conditions for the low-frequency series of a component test. 
Axis $x$ diccoleromeler interaction

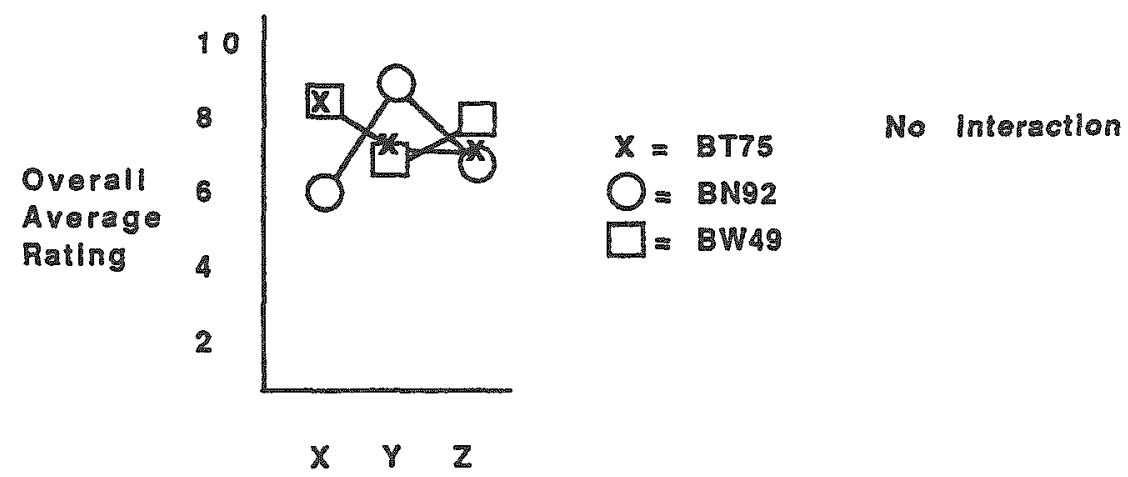

Axls x Pressure Interaction

Averall
Average
Rating

$X \quad Y \quad \mathbb{Z}$

Axis zixture Interaction

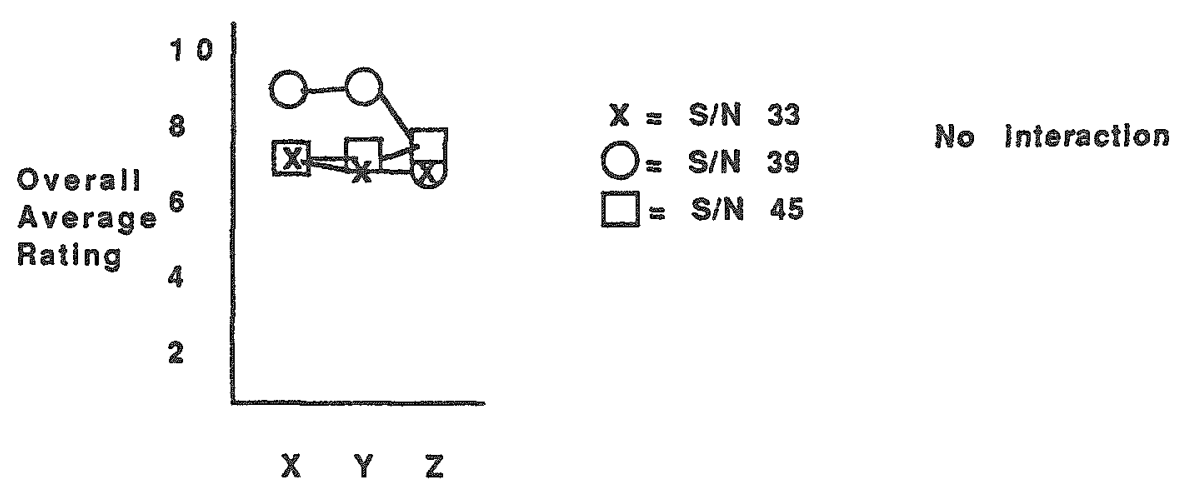

Figure 9 - Tests for interactions of experimental factors for Low-frequency runs. 


\section{Analysis of Acceleration vs. Frequency Data}

Each of the impulses from the shots is transformed into frequency data that can be characterized by a few numbers. For the HF series, the data that range from 300 to $10000 \mathrm{~Hz}$ are well characterized by 14 discrete frequencies; whereas for the LF series, that data is well characterized by 9 frequencies. An evaluation of the main effects is accomplished using the Taguchi matrices on Tables 2 and 3 for each individual frequency. As an example of the type and quantity of information, the data for one frequency, $2500 \mathrm{~Hz}$, are listed in Table 4. This analys is allows the results to be quantitatively compared to tolerance limits at each frequency. Thus, for evaluating a main effect, one averages the acceleration results of the appropriate rows of the Taguchi L-27 matrix. For example, to obtain the effect of "axis," one obtains the average measured accelerations for Rows 1 through 9 ( $\mathbb{X}$ axis), 10 through 18 ( $Y$ axis), and 19 through 27 ( $Z$ axis). For "pressure," one averages the result of Rows $1,4,7,10,13,16,19,22$, and 25 for 17 psi, 2,5,8,11,14,17,20,23, and 26 for $20 \mathrm{psi}$, and $3,6,9,12,15,18,21,24$, and 27 for $23 \mathrm{psi}$. The appropriate combinations for the other three factors can be derived from columns 2,8 , and 9 .

The average for each frequency can be plotted on a graph, and an evaluation of the effect of changing experimental parameters on measurement performance can be observed. An evaluation of each factor, based on graphical analyses, is discussed in the following section. Tolerance levels are plotted on these graphs to provide a basis for judging whether a significant difference is important in meeting specifications. Each point plotted on these graphs is typically the average of 36 shots.

\section{High Frequency $(300-10000 \mathrm{~Hz})$}

Axis: The average responses for the three axis configurations for the high-frequency test are plotted in Figure 10. The symbols 1,2 , and 3 on 


\begin{tabular}{|c|c|c|c|c|c|}
\hline DOX & Trial & Shot 1 & Shot 2 & Shot 3 & Shot 4 \\
\hline 1 & 2 & $5100 \mathrm{~g}$ & $5100 \mathrm{~g}$ & $5000 \mathrm{~g}$ & $5300 \mathrm{~g}$ \\
\hline $\begin{array}{l}2 \\
3\end{array}$ & 2 & 3900 & 4100 & 4100 & $\cdots$ \\
\hline $\begin{array}{l}3 \\
4\end{array}$ & 1 & 7900 & 7900 & $\cdots$ & 8000 \\
\hline $\begin{array}{l}4 \\
5\end{array}$ & 1 & 3300 & 2400 & 3200 & 3400 \\
\hline $\begin{array}{l}5 \\
6\end{array}$ & 1 & 7000 & 7000 & 7000 & 6900 \\
\hline $\begin{array}{l}6 \\
7\end{array}$ & 1 & 6000 & 5400 & 6000 & 6050 \\
\hline $\begin{array}{l}7 \\
8\end{array}$ & 1 & 4000 & 4100 & 4900 & 5000 \\
\hline $\begin{array}{l}8 \\
9\end{array}$ & 1 & 6800 & 7000 & 6900 & 7000 \\
\hline $\begin{array}{l}9 \\
10\end{array}$ & 1 & 5000 & 5200 & 5000 & 5000 \\
\hline $\begin{array}{l}10 \\
11\end{array}$ & 1 & 3800 & 3200 & 3800 & 3900 \\
\hline $\begin{array}{l}11 \\
12\end{array}$ & 1 & 6800 & 6700 & 6600 & 6400 \\
\hline $\begin{array}{l}12 \\
13\end{array}$ & 1 & 7900 & 6600 & 6600 & 6900 \\
\hline 13 & 1 & 5000 & 5050 & 5050 & 5400 \\
\hline 14 & 1 & 6300 & 6300 & 6800 & 7000 \\
\hline 15 & 1 & 4700 & 5050 & 5000 & 5000 \\
\hline 16 & 1 & 4800 & 5000 & 5000 & 4900 \\
\hline 17 & 1 & 5300 & 5100 & 5400 & 5100 \\
\hline 18 & 1 & 7000 & 7200 & 7700 & 7700 \\
\hline 19 & 1 & 3800 & 4500 & 4900 & 5000 \\
\hline 20 & 1 & 6300 & 6200 & 6100 & $\cdots$ \\
\hline 21 & 1 & 4900 & 3050 & $\cdots$ & 5800 \\
\hline 22 & 1 & 4400 & 4400 & 4500 & 4600 \\
\hline 23 & 1 & 4700 & 3900 & 4050 & 4150 \\
\hline 24 & 1 & 6000 & 7000 & 6500 & 6000 \\
\hline 25 & 1 & 3000 & 3600 & 3000 & 3050 \\
\hline 26 & 1 & 5100 & 5500 & 5800 & 5000 \\
\hline 27 & 1 & 6900 & 7000 & 7000 & 7000 \\
\hline
\end{tabular}




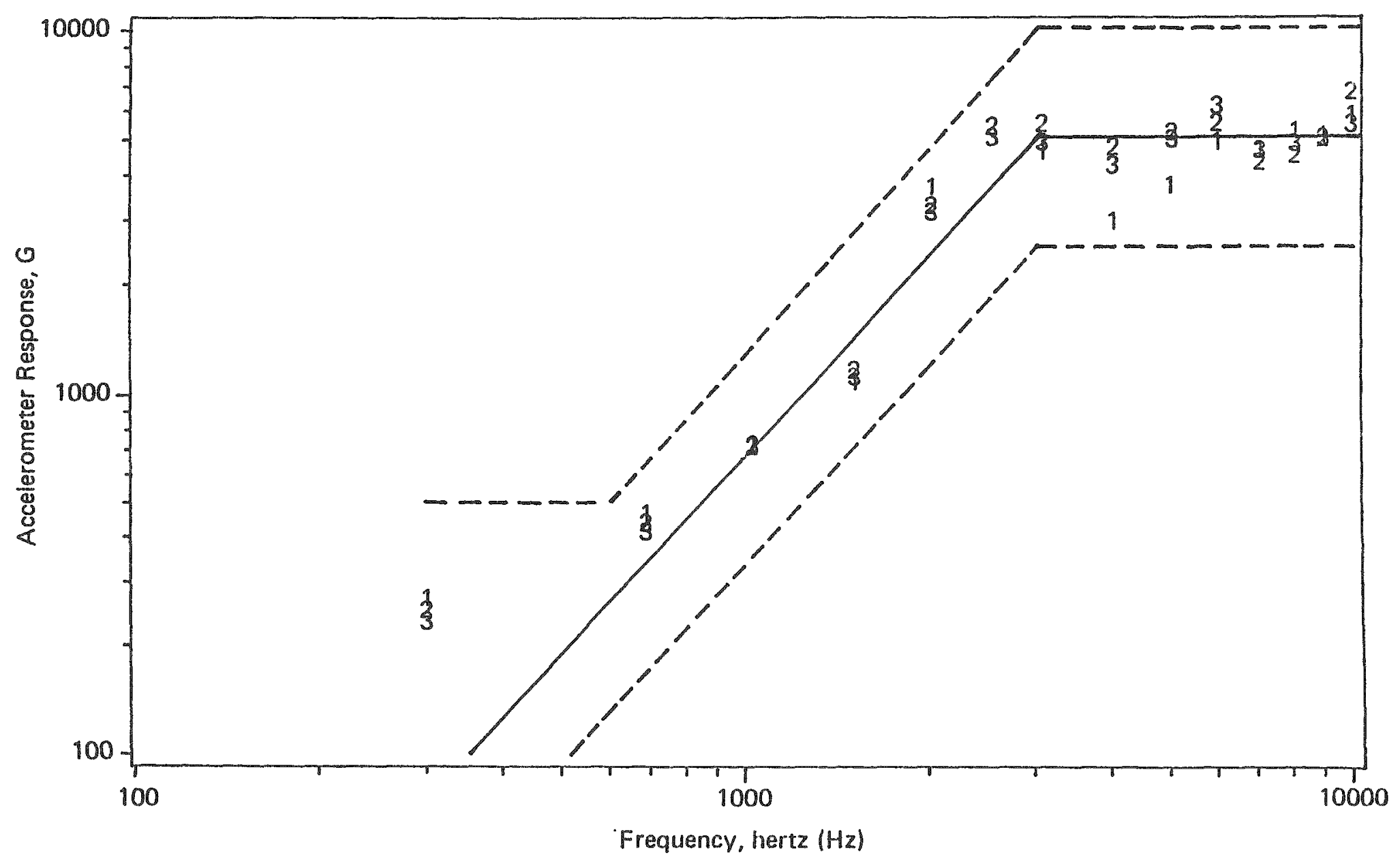

Figure 10 - Average acceleroneter response with high-frequency plate for three axis configurations. 
this plot correspond to the average response at a particular frequency of the $X, Y$, and $Z$ axis configuration, respectively. The overlapping numbers on this graph are a rough indication that there is no statistically significant difference in response because of the axis configuration. This was supported by a statistical Analysis of Variance (ANOVA) that was performed on the data set. Well separated numbers indicate that there is an effect. Thus, at a frequencies of 4000 and $5000 \mathrm{~Hz}$ in Figure 10, the relatively large separation of the average response level 1 ( $X$ axis) from the other two levels, and the proximity of the $4000 \mathrm{~Hz}$ result to the lower tolerance limit, indicate that more out-of-tolerance measurements may be made with that axis configuration.

Accelerometer: The results are plotted in Figure 11 for the three accelerometers. There is no significant difference.

Pressure: A significant difference in response was noted for the firing pressure. The results plotted in Figure 12 show that for the lowest firing pressure, ( $1=17 \mathrm{psi})$ the least acceleration is obtained over al1 frequencies. For the higher pressures, (2=20 psi, $3=23$ psi) there are progressively larger accelerations. Since a higher firing pressure leads to a faster bullet and, hence, more impulse at contact with the plate, this result is in line with physical principles. The lowest pressure condition leads to results closest to the tolerance limit and hence is the least desirable of the three conditions.

Fixture: No significant difference was observed. Any of the three fixtures would give the same results (Figure 13).

Plate Angle: From Figure 14, a main effect is seen for the plate angle. The lowest accelerations are obtained with the $5^{\circ}$ orientation of the plate to the bullet path over all frequencies. There is no difference in average response between the $0^{\circ}$ and $2.5^{\circ}$ angles. In selecting the appropriate angle for testing, the $0^{\circ}$ angle would be preferred because any small error in setup of 


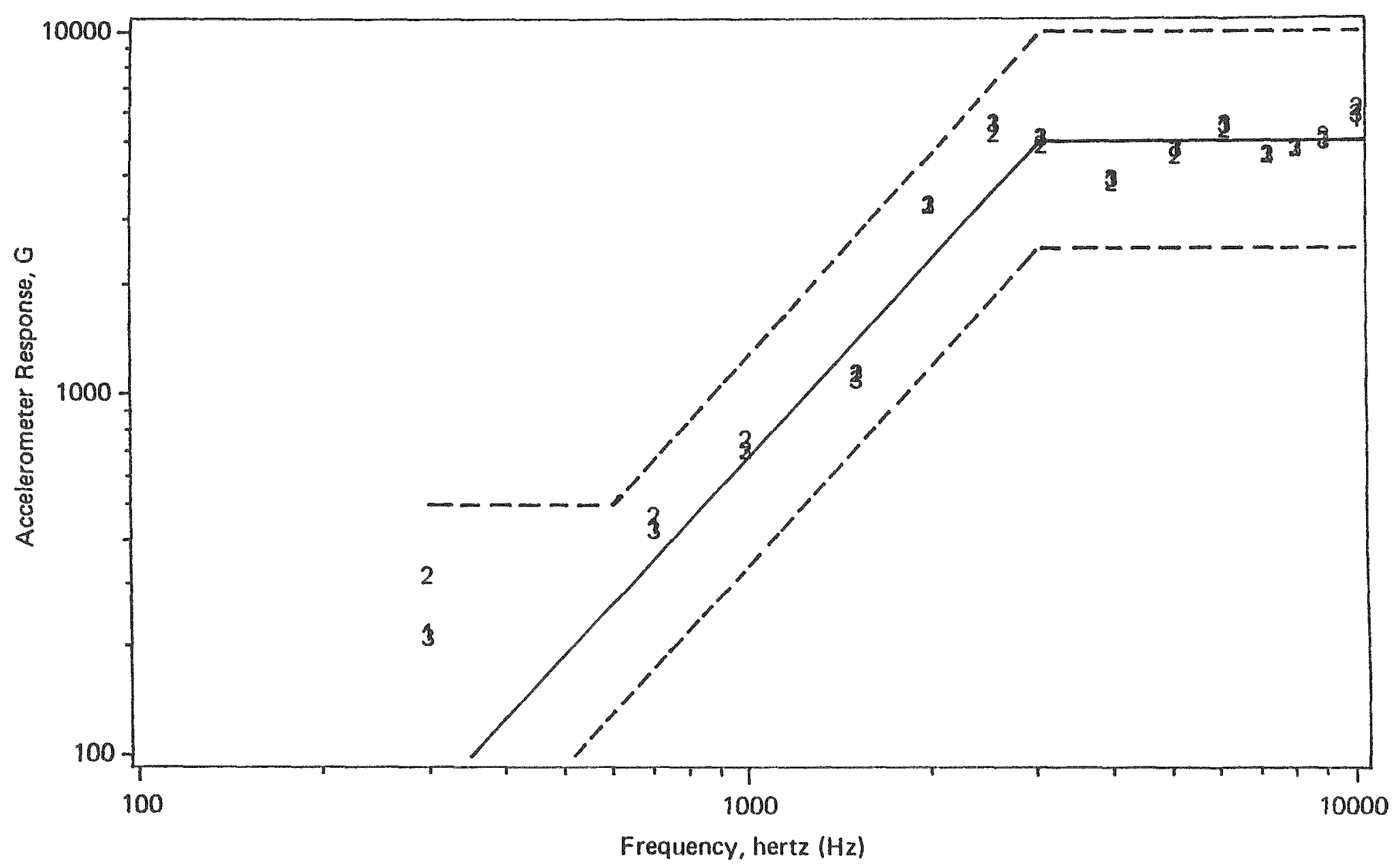

Figure 11 - Average accelerometer response with high-frequency plate for three different accelerometers. 


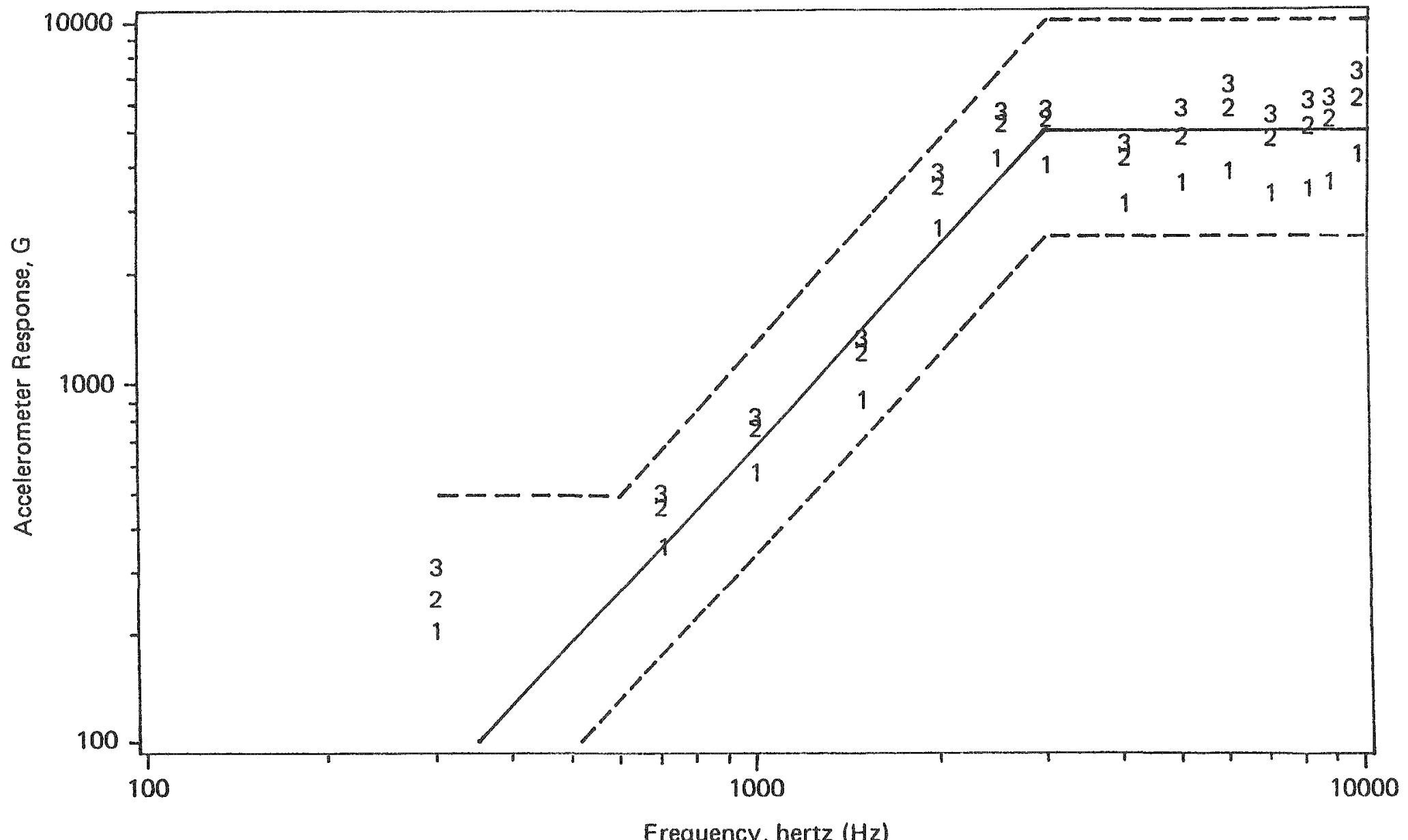

Frequency, hertz $(\mathrm{Hz})$

Figure 12 - Average accelerometer response with high-frequency plate For three different charge pressure $(1=17 \mathrm{psi}, 2=20 \mathrm{psi}$, and $3=23$ psi). 


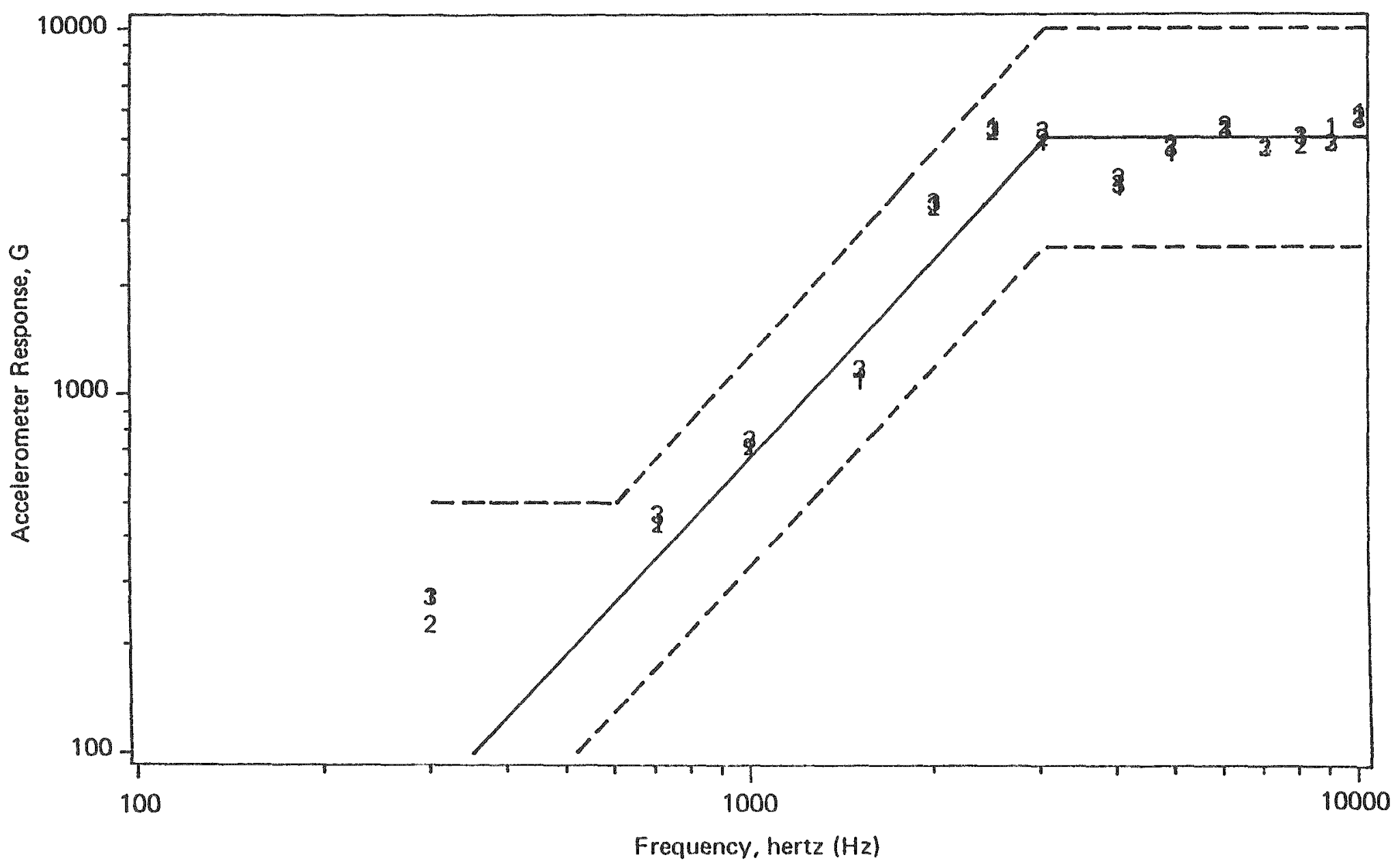

Figure 13 - Average accelerometer response for three different fixtures using high-frequency plate. 


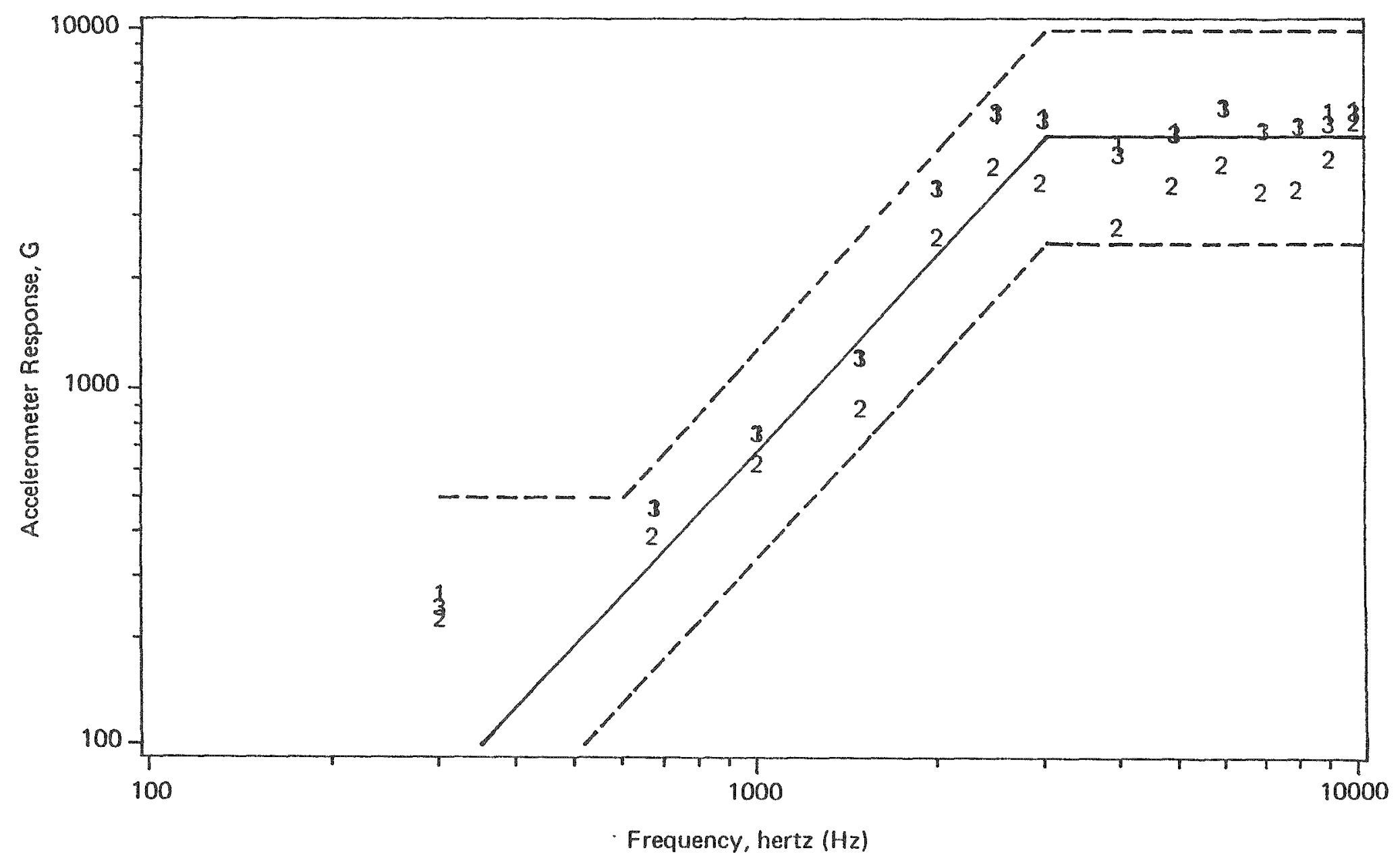


this angle will not affect the results. A slight error in the $2.5^{\circ}$ angle toward a greater angle could lead to a bad result since there is a sudden change in response somewhere between $2.5^{\circ}$ and $5^{\circ}$ possibly caused by the edge of the bullet striking the plate at the largest plate angle.

\section{Interactions}

other graphs were plotted corresponding to the unassigned columns of the Taguchi matrix which can be used to estimate second order interactions. No effects were seen.

\section{Low Frequency $(300-2000 \mathrm{~Hz})$}

Axis: Increasingly larger differences were seen between the response due to axis configuration toward lower frequencies. In the lower frequency range, the acceleration is significantly higher for the $X$ axis configuration, coded as 1 . The results for the $Y$ and $Z$ axis configurations are relatively close to the lower tolerance 1imit. (Figure 15)

Accelerometer: A difference hetween accelerometer response for BN92 was observed at the lowest frequencies, but the magnitude of the separation is within the statistical noise at this rrequency. (Figure 16)

Pressure: A signification difference in response was noted for the firing pressure over all frequencies. Progressively higher accelerations were noted for increasingly higher pressures. There is no optimum pressure at all frequencies.

At 500 to $1500 \mathrm{~Hz}$, condition 1, equal to $30 \mathrm{psi}$, gives the results closest to the target acceleration, whereas conditions 2 , equal to $35 \mathrm{psi}$, or 3 , equal to 40 psi, are superior at other frequencies. (Figure 17) 


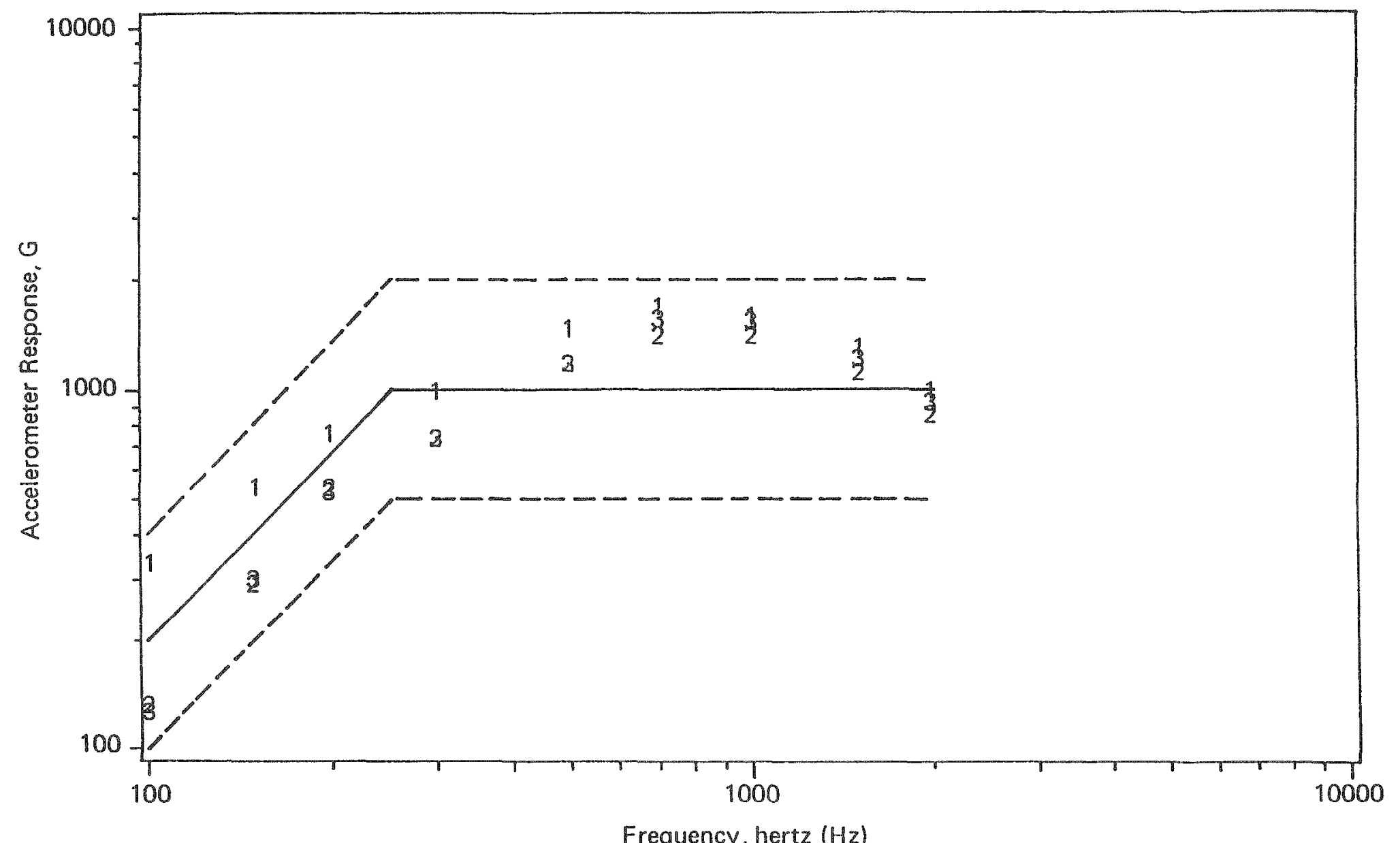

Figure 15 - Average accelerometer response with low-frequency plate for three different axis configurations. 


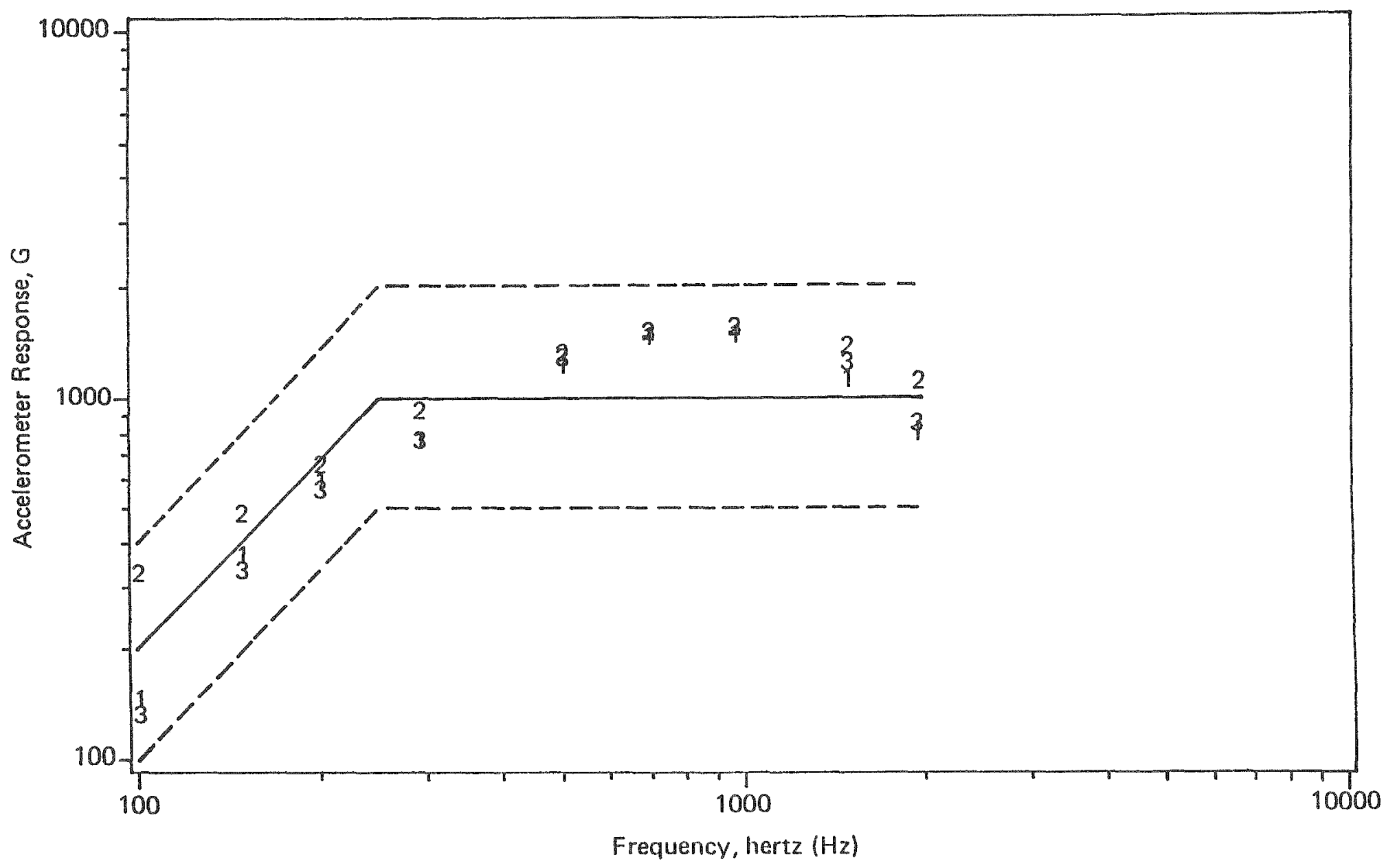
Figure 16 - Average accelerometer response with low-frequency plate
for three different accelexometers. 


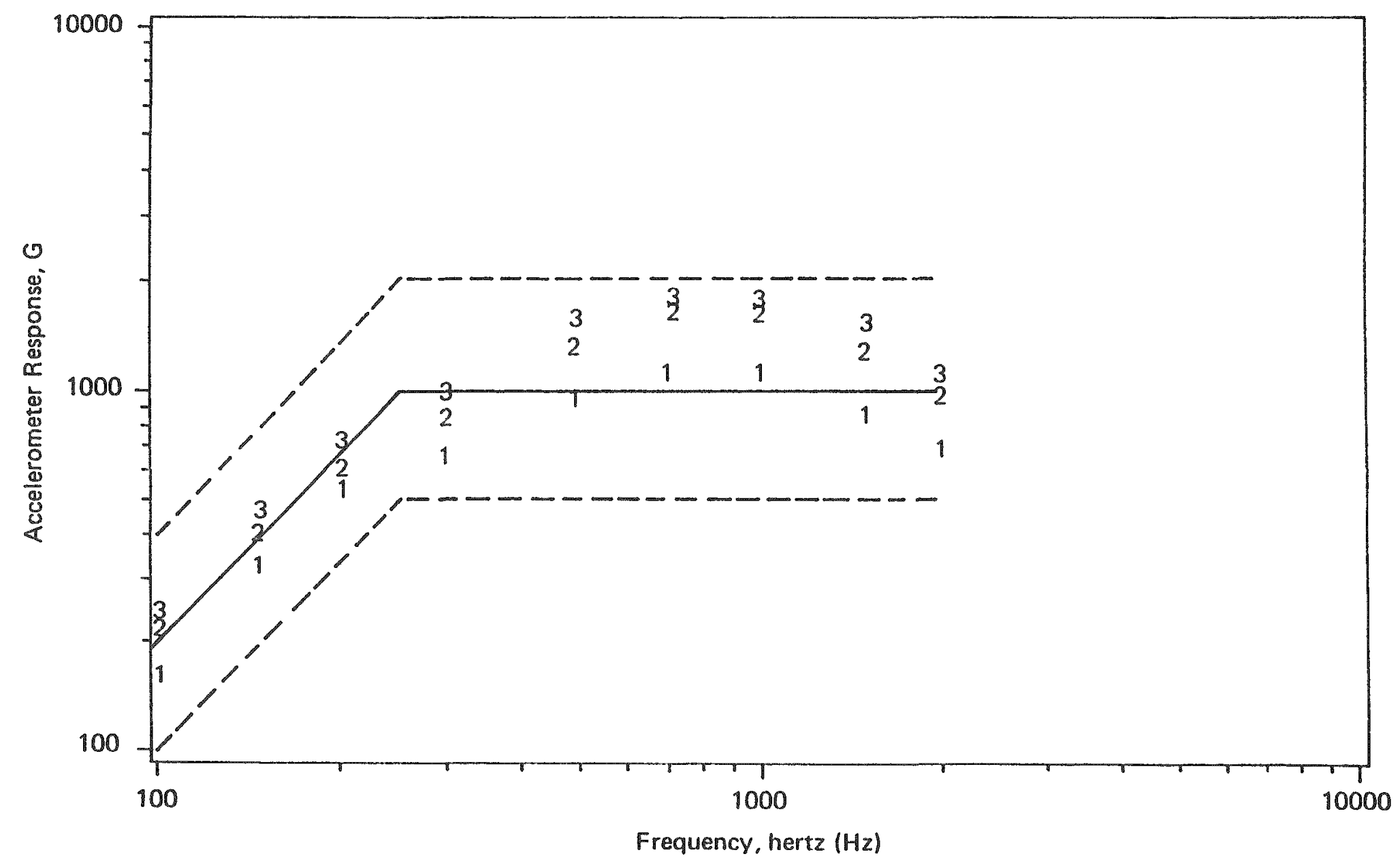

Figure 17 - Average accelerometer response for low-frequency plate for three different charge pressures ( $1=30$ psi, $2=35$ psi, and $3=40$ 
Fizture: A difference in average response was observed at the lowest frequency, but the differences are well within the tolerance bands so the difference is not of practical significance. (Figure 18)

Plate Angle: A main effect is seen for the plate angle. The smallest accelerations are obtained with the $5^{\circ}$ orientation of the plate to the bullet path. This result is consistent with the HF series of runs, but the resultant acceleration in this case is not as unfavorable. This plate angle yielded accelerations closest to the midpoint of the tolerance band from 500 to $1500 \mathrm{~Hz}$ but gave inferior results at other frequencies. (Figure 19)

\section{Interactions}

No second order effects were seen when the unassigned columns of the Taguchi Matrix were graphically analyzed as above.

Ont]ier Rejection Procedure

In addition to the impulse delivered to the plate by the bullet, the transit time of the bullet between two fixed points in the barrel is measured by means of two photocells set in the gun barrel wall. The transit times for the HF shots are plotted as a function of firing pressure in Figure 20 . A few data points on this graph appear to have significantly slower transit times. In reviewing the froquency data, among replicate shots, occasionally the measured accelerations for one shot appeared significantly lower than the others. The outlying slow transit times correlate well with the discrepant data. Thus, the transit times provide a means of discarding data resulting from misfires. The data from five shots of 5 out of $109 \mathrm{HF}$ shots and 3 out of 108 LF shots were not used in the analysis due to this discrepancy. Bullet transit times thus are a diagnostic indicator that can be used for rejecting certain types of misfires. Misfires could result from a bullet not being properly reseated after the previous shot or from an abnormally slow release of charge pressure to drive the bullet. 


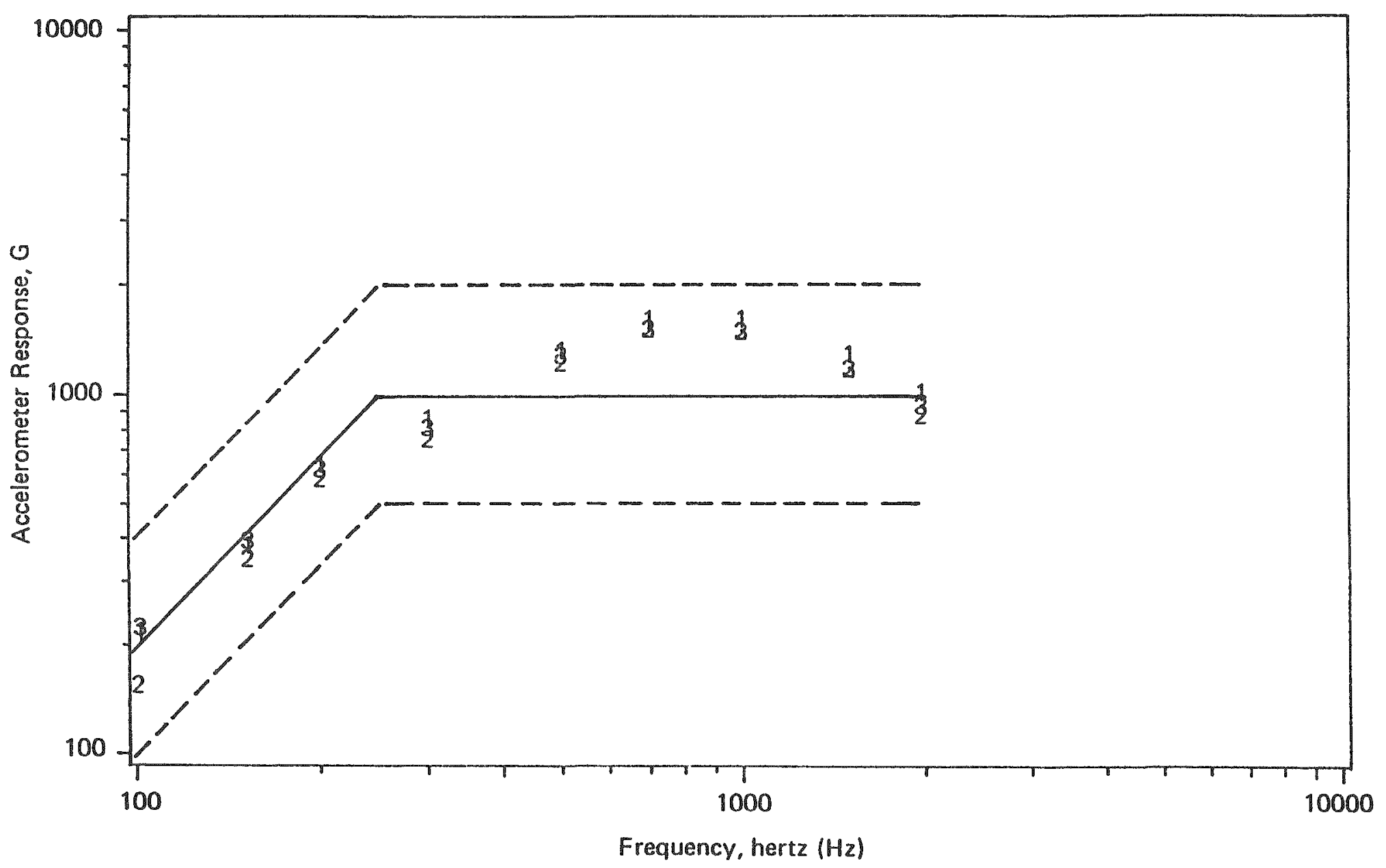

Figure 18 - Average accelerometer response with low-frequency plate for three different fixtures. 


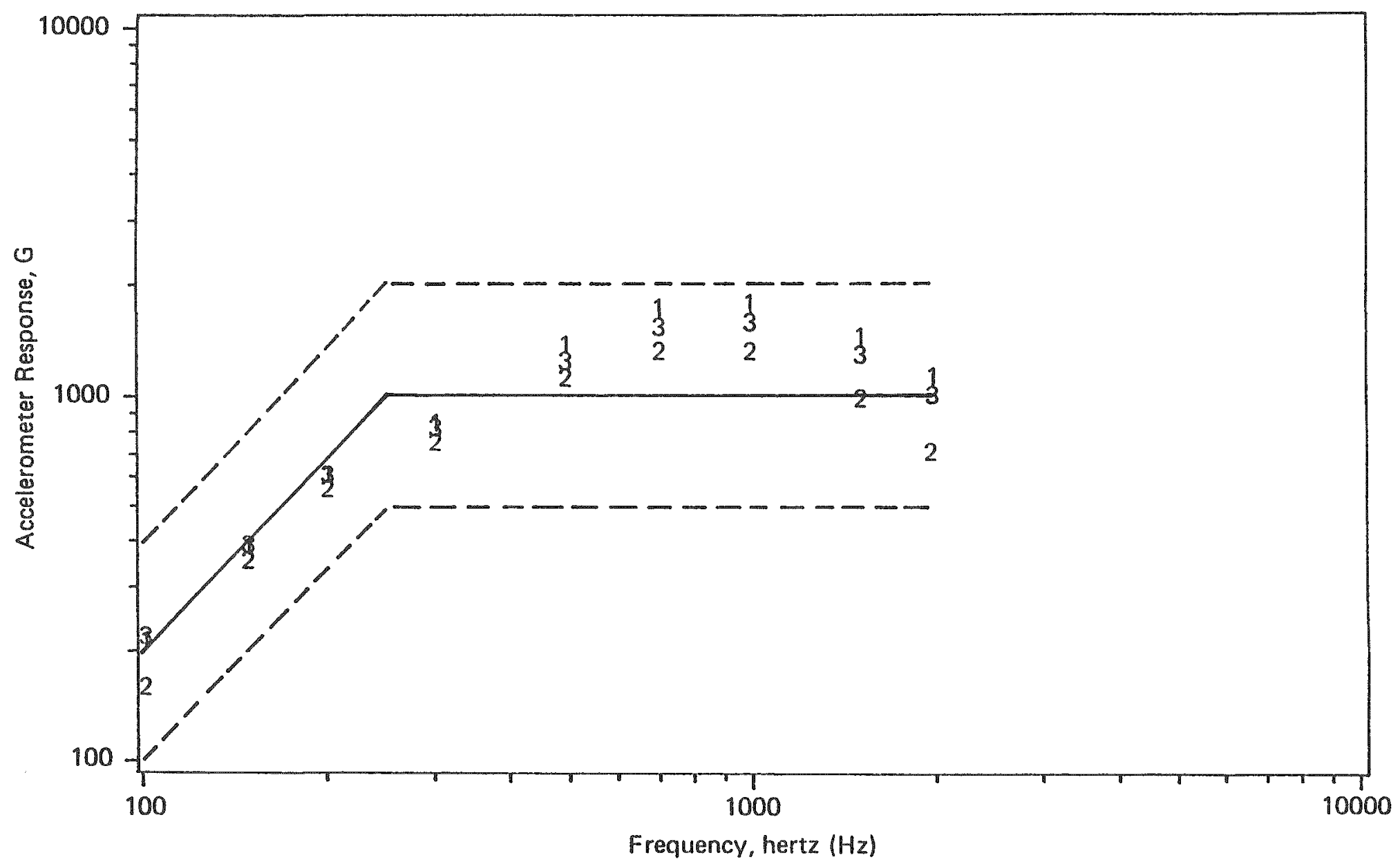

Figure 19 - Average accelerometer response with low-frequency plate for three different plate angles $\left(1=0^{\circ}, 2=5^{\circ}\right.$, and $\left.3=2.5^{\circ}\right)$. 


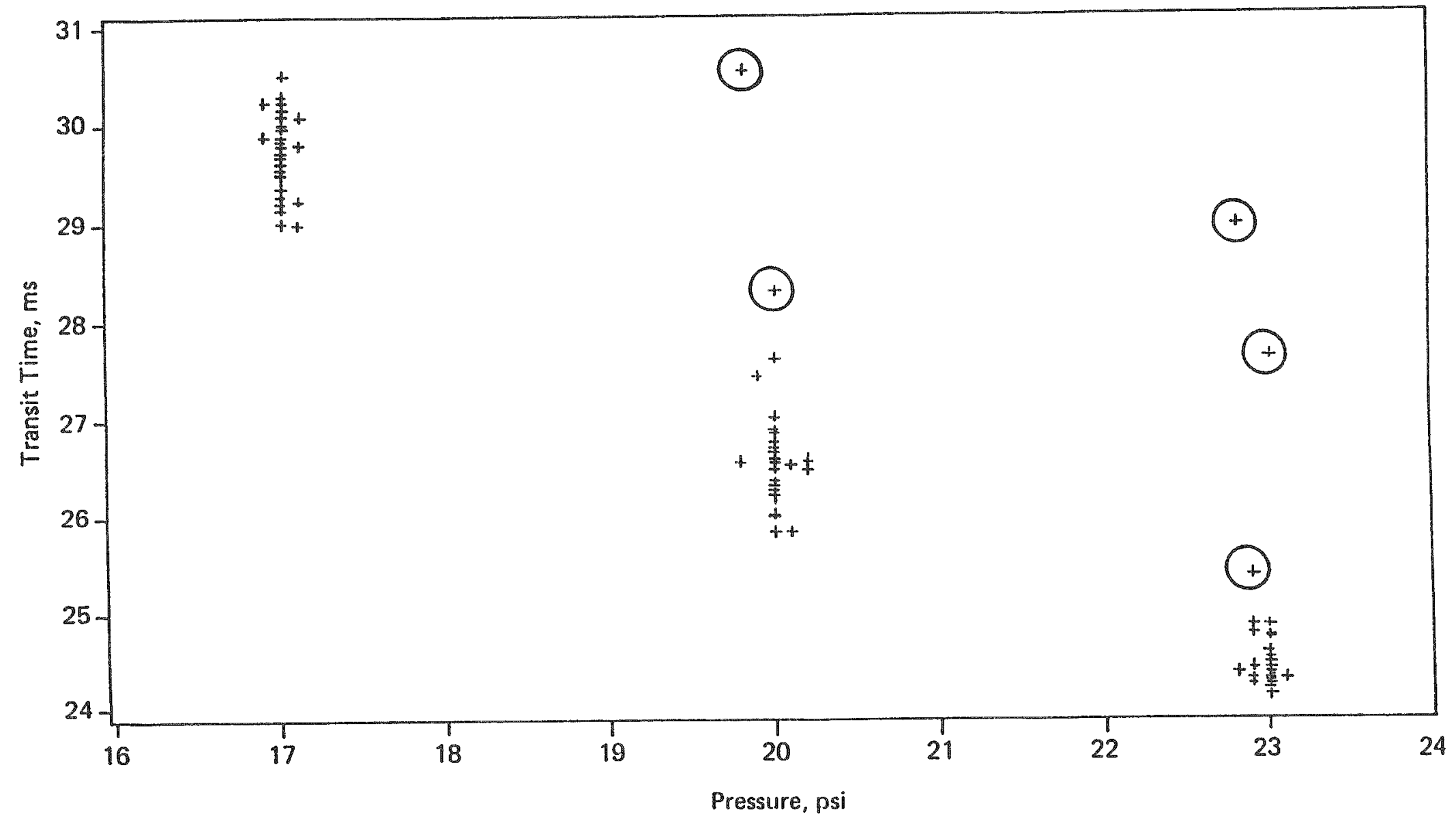

Figure 20 - Transit times for the high-frequency test shots as a function of firing pressures; the transit time of the bullet is measured between two fixed points in the barrel by means of two photocells set in the gun barrel wall. (Circled data points are outliers.) 


\section{Selection of Standard Operating Condition}

Pressure and plate angle were the two factors that could be tuned to produce satisfactory results. Both the analysis based on the rating of the results and the more detailed frequency analysis indicated that the best conditions for operation at the High Frequency part of a component test is with a driving pressure of $20 \mathrm{psi}$ and a plate angle of $0^{\circ}$. More alternatives for these factors were possible for the Low Frequency analyses because the optimal factor settings at one frequency would be less favorable at others. The most extreme angle $\left(5^{\circ}\right)$ and lowest pressure gave the best results in part of the LF acceleration spectra, but the other conditions were more favorable in other areas of the spectra. For the LF runs, the $0^{\circ}$ angle was chosen as the optimum to minimize possible downtime required for setup, as the plate angle would not have to be changed between the LF and HF runs. The 35 psi driving pressure was chosen as the driving pressure because it produced better overall results. Although the lower pressure yielded better results, it gave less satisfactory results at other frequencies.

\section{Experimental Observations}

During previous testing, it was noted that since the bleed off of the charge cylinder was not always easy to control, firing at the targeted pressure was a "hit-or-miss" activity. If $20 \mathrm{psi}$ was the targeted fire pressure, the tester could actually be fired at 18 or 19 psi depending on (1) the bleed rate of the fire pressure reservoir or (2) the reaction time of the operator perforning the test. It was found to be very important to set all regulators in the systems so that the bleed off is well controlled, and the targeted rire pressure will be tasily achieved. Autonatic rather than manual firing could remove this problem. 
The impact pad was found to have a tendency to loosen after many hits. In one shot, the impact pad was found to be loose and the results yielded unacceptably low accelerations. The operating procedure was changed so that prior to beginning each test sequence, the impact pad was checked to ensure that it was tight. During these experiments, a standard torque pattern was followed when attaching the fixture to the resonant plate. This tightening pattern has been incorpoxated into the operating procedures.

The $\mathrm{X}$ axis configuration for the fixture/component results in these experiments had a different "footprint" on the resonant plate compared to the $Y$ and $Z$ axes. Addition of a spacer of appropriate dimensions to provide the same interface with the plate may remove the differences observed in the HF runs. Individual test shot data for the experiment can be found on microfiche located in Drawing Control.

\section{Acknowledgments}

The authors of this report wish to thank Jack Elliot, instructor of the Experimental Design class, for his input in helping to analyze and interpret the effects and interaction graphs. 


\section{References}

1. Genichi Taguchi, "System of Experimental Design," Vol. 2, page 1154, UNIPUB/Kraus, 1987.

2. J. G. Elliot, "Statistical Methods and Applications," copyrighted lecture notes, Allied-Signal, Inc. (1987). 


\section{Distribution}

\section{External}

OSTI, UC-706 (118)

J. G. Elliot, Allied-Signal, Inc.

J. A. Morley, DOE/DAO

\section{Sandia National Laboratories. Albuquerque}

S. G. Barnhart

F. H. Braten

J. E. Curzi

G. E. Dahms

N. T. Davie

D. E. Hoke

D. E. Mitcrell

\section{Interna1}

M. E. Babcsck

D. E. Benn?r

T. M. Brugjeman

J. J. Carliston

A. F. Ciranella

M. F. Duff

D. J. Esposito

R. J. Finn $\equiv y$

R. A. Fisc bein

L. Fox

T. M. Fritsch

D. M. Gall ther

E. A. Hawley

J. A. Helgerson

E. D. Hill

D. L. Michaels

D. E. Michel

G. L. Morris

K. A. Muncy

C. R. Rudy

S. I. Snow

C. P. Strong

R. E. Vallee

H. A. Woltermann

W. Yurkowsky, Jr.

Document Control

Publications 